\title{
STRAIN DISTRIBUTIONS IN HOT ROLLED ALUMINUM BY PHOTOPLASTIC ANALYSIS
}

Adeyinka Kofoworola Oyinlola

M. S. Thesis Submitted to Iowa State University

\author{
Ames Laboratory, USAEC \\ Iowa State University \\ Ames, Iowa 50010
}

Date Transmitted: October 1974

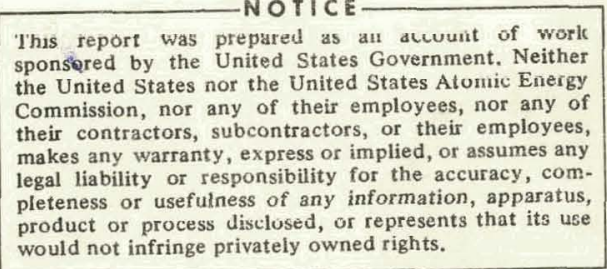

PREPARED FOR THE U.S. ATOMIC ENERGY COMMISSION DIVISION OF RESEARCH UNDER CONTRACT NO. W-7405-eng-82 


\section{DISCLAIMER}

This report was prepared as an account of work sponsored by an agency of the United States Government. Neither the United States Government nor any agency Thereof, nor any of their employees, makes any warranty, express or implied, or assumes any legal liability or responsibility for the accuracy, completeness, or usefulness of any information, apparatus, product, or process disclosed, or represents that its use would not infringe privately owned rights. Reference herein to any specific commercial product, process, or service by trade name, trademark, manufacturer, or otherwise does not necessarily constitute or imply its endorsement, recommendation, or favoring by the United States Government or any agency thereof. The views and opinions of authors expressed herein do not necessarily state or reflect those of the United States Government or any agency thereof. 


\section{DISCLAIMER}

Portions of this document may be illegible in electronic image products. Images are produced from the best available original document. 
This report was prepared as an account of work sponsored by the United States Government. Neither the United States nor the United States Atomic Energy Commission, nor any of their employees, nor any of their contractors, subcontractors, or their employees, makes any warranty, express or implied, or assumes any legal liability or responsibility for the accuracy, completeness or usefulness of any information, apparatus, product or process disclosed, or represents that its use would not infringe privately owned rights.

Available from: National Technical Information Service Department A

Springfield, VA 22151

Price: Microfiche $\$ 2.2 .5$ Paper copy $\$ 5.45$ 

Strain distributions in hot rolled aluminum by photoplastic analysis by Adeyinka Kofoworola Oyinlola

\author{
A Thesis Submitted to the \\ Graduate Faculty in Partial Fulfillment of \\ The Requirements for the Degree of \\ MASTER OF SCIENCE \\ Department: Metallurgy \\ Major: Metallurgy (Mechanical Metallurgy)
}

\begin{abstract}
Approved:
\end{abstract}
In Charge of Major Work

For the Major Department

For the Graduate College

Iowa state University

Ames, Iowa

1974 
TABLE OF CONTENTS

Page

ABSTRACT

INTRODUCTION AND LITERATURE REVIEW

Mechanics Aspects

Photoplastic Techniques

EXPERIMENTAL PROCEDURE

Compression of Rectangular Blocks

Compression of Cylindrical Samples

Compression of Discs

Rolling of the 60:40 Mixture

Photographic Materials and Methods

Compression of Rectangular Blocks

Compression of Cylindrical samples

Compression of Discs at $40^{\circ} \mathrm{C}$

Rolling of the 60:40 Mixture

REFERENCES

ACKNOWLEDGMENTS

APPENDIX A

Figures

The Determination of the Material Fringe constant $f_{\varepsilon}$ 


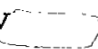

\begin{abstract}
*
A previously developed photomechanic material, Laminac, which excellently simulates the behavior of aluminum in tension has been investigated intensively as a possible modeling material for hot-rolled aluminum billets. Photoplasticity techniques combined with the Moiré method have been used to study the behavior of the Laminac mixture in compression. Photoplastic analysis revealed that a Laminac mixture of $60 \%$ flexible and $40 \%$ rigid resins, compressed or rolled at $40^{\circ} \mathrm{C}$, showed the phenomenon of double buiging which has been observed in hot-rolled aluminum billets. The potentiality of the 60:40 Laminac mixture as a possible simulating material at $40^{\circ} \mathrm{C}$ is further enhanced by the fact that the true stress-true strain curves of cylindrical samples compressed at $40^{\circ} \mathrm{C}$ correlated very well with true stress-true strain of identical cylindrical samples of aluminum compressed at $300^{\circ} \mathrm{C}, 425^{\circ} \mathrm{C}$ and $500^{\circ} \mathrm{C}$.
\end{abstract}

* USAEC Report IS-T-640. This work was performed under contract $W-7405-e n g-82$ with the Atomic Energy Commission. 


\section{INTRODUCTION AND LITERATURE RFVIEW}

During the last decade substantial experimental work has been done in order to determine how the variables inherent to the material (composition, size, shape, structure) and the variables inherent to the process (rate of strain, stress system; lubrication and temperature) influence hot workability in such operations as rolling, forging, pressing, extrusion and wire or bar drawing. Some of the investigations involved laboratory simulations of commercial rolling, extrusion, and forging operations. The virtue of laboratory simulations is that they incorporate factors, such as friction, which are difficult to isolate and control by any experimental method except a scaled down version of the actual process. Other investigations involved basic materials tests such as tension, compression, torsion and bending; these have the virtue that variables such as strain rate and temperature can be controlled, and the deformations are more uniform and easily measured. These experimental studies have improved our understanding of two characteristics, strength and durtility, that qovern hot workability.

A survey of the literature regarding hot-rolling re-. vealed that a complete strain distribution has not been established even for unidirectionally rolled billets (1). Presumably this is a consequence of the fact that no reliable 
method is available for establishing three dimensional strain distributions associated with different sequences of rolling or, for that matter, for most forming operations. A simulative material as well as an experimental technique with the capability for providing three-dimensional strain distributions is sorely needed. A thorough understanding of the three dimensional strain or stress distribution obtained with a modeling material could help solve some of the problems encountered during hot rolling in commercial practice.

\section{Mechanics Aspects}

Most theories of rolling are concerned with predicting the load and torque required by the rolling mill, and possibly the lateral spread when plates having width to thickness ratios larger than 6 or 10 are rolled. Furthermore, practically all theories have relled upon a number of basic assumptions, e.g.: The metal being formed is a continuous isotropic medium; homogeneous deformation; constant yield stress during the pass; circular arc of contact; mathematical approximations; constant coefficient of friction along the arc of contact; plane strain by neglecting lateral spread; the Huber-Von Mises condition of plasticity; slipping takes place along the length of the arc of contact; elastic compression of the strip is negligible; small contact angle and constant speed of rolling. When rolling sections which have 
width to thickness ratios less than 6 , such as is common in hot rolling of ingots into billets, the theoretical predictions become unreliable and predictive work has to resort to empirical formulas with limited ranges of application. The most recent empirical. formulations are due to El-Kalay and Sparling. (2), Helmi and Alexander (3) and Beese (4). The rolling process is complicated, by many factors, to the extent that it is not possible to obtain a solution for even the relatively simple problem of flat rolling. and a proved, accurate, general solution is not yet known. Twodimensional states of strain or stress have been described analytically for the rolling process using the aforementioned assumptions (1). Knowledge of three-dimensional strain or stress states and how they vary with work piece geometry and other process variables will help improve existing theories and probably will lead to the development of new theories or accurate numerical methods such as the finite element approach.

A variety of methods have been used by different investigators to gain information about the strain distribution within a body undergoing plastic deformation during hot rolling. Experimental techniques employed to obtain this type of information typically involve the placement of grids of one material into another model material. The composite material is deformed, sectioned, and the displacements, 
usually in only two dimensions, are measured. For example, Averbach (5) determined the distribution of principal strains within a cast bar of tin by radiographing an embedded network of lead containing squares approximately $2.1 \mathrm{~mm}$ wide (144 network squares per sq. in.) after a $20 \%$ rolling reduction. His results were computed from only two vertical sections where he was able to evaluate the longitudinal and vertical strains directly from the radiographs. The lateral strains were totally neglected based on the fact that they were too small for accurate measurement. Instead, he evaluated the lateral strains by invoking the constancy of volume condition. This condition would have to be in error by $50 \%$ to account for the observed lateral strains; however, deviations of this magnitude were not observed.

Orowan, (6) studied plastic flow in rolling by partrolling wide slabs composed of alternate layers of gray and white plasticine between unpolished wooden rolls. These conditions established a coefflclent of rriclion greater than one, thereby providing for complete sticking to occur. After the laminated plasticine slabs were part-rolled, they were withdrawn from the rolls and split longitudinally at the center line to reveal the strain distribution. Orowan neglected observations which were not amenable to analysis within the framework of the mathematical formulation of his rolling theory. For example, the deformation which occurred 
at the entry side of the mill where the material is squeezed backwards out of the roll gap could not be incorporated in his analysis. Furthermore, he assumed a small angle of contact but obtained large angles of contact in his experiment. This led to considerable error in his calculations. An analysis appropriate to large angles of contact needs to be formulated. Nevertheless, Orowan's theory of roling seems to stand as the best available.

\section{Photoplastic Techniques}

Photoelasticity is that branch of experimental stress analysis which utilizes the phenomenon exhibited by some transparent materials which are optically isotropic when free of stress but become temporarily birefringent (i.e., they are temporarily doubly refractive) in the directions of the principal strains or stresses when loads are applied to them.: Models made from such materials can therefore be used to obtain information regarding the stress or strain distributions in materials subjected to various system of loads $(7,8)$. When viewed in a field of polarized light, the birefringence manifests itself as an optical interference pattern of light and dark bands called fringes which may be due to stress, strain, or a combination of the two, depending on the model material being used. 
There arise two simultaneous sets of interference fringes which are generally called "isochromatics" and "isoclinics." It has been established that in the region of linear elastic response the isochromatics are proportional to the in-plane maximum shear stresses while the isoclinics give the inplane principal stress directions. The two sets of fringes can be separated by suitable arrangement of the optical elements of the polarized light field or "polariscope." The quantitative relationship, which has been shown to exist between the stress and/or strain state and the optical effect, provides a precise experimental means for evaluating stress or strain distributions in extremely complicated two- or threedimensional configurations. The method of photoelasticity has been applied to a wide variety of engineering problems which proved difficult or impossible to solve by analytical means. The method often provides new insight to difficult problems leading to additional mathematical development.

Experimental evidence to date indicates that the optical effects produced by stress and/or strain in transparent materials exists for both elastic and plastic deformations. Hetenyi (9) used the results of tensile tests to study plastic strains in a nylon copnlymer. He found that the isochromatics could be related to the strain distribution in this material. Emphasis in his study was placed on optical indications of 
yielding. Fried and Shoup (10) used polyethylene to study the photoelastic effect in a region of large deformation, and found that the optical retardation varied linearly with the principal strain difference well beyond the range of linear stress strain behavior. Photoelastic model predictions of strain distributions compared favorably with those present in an aluminum prototype. More recently Brill (11) selected polycarbonate as the model material for basic studies in one- and two-dimensional photoplasticity. He concluded that the birefringence is a function only of the principal strain difference and that the isoclinic parameter provided a measure of the principal strain directions. A tensile specimen with a central circular hole was used and the photoplastic results were compared with test results from metallic analogues. Good agreement was obtained. Recently Ohashi and Nishitani (12) determined the stress state within a plastically flowing body in plane strain by a photo-rheological method. They rolled $6 \mathrm{~mm}$ thick celluloid plates subjected to forward tension as well as rolling torque. They determined stresses in two dimensions and showed the effect of the applied tension on their distribution, both in the rolls and in the strip specimens. The method by which they restricted the deformation of the strip to obtain plane strain needs further investigation to evaluate the effect of the constraint on the strain distribution in the strip during 
rolling. The experiment was carried out at only one temperature $\left(65^{\circ} \mathrm{C}\right)$. The variation of stress distribution with temperature also needs further investigation. Only one work-piece geometry, where the length is many times greater than the breadth, has been accounted for in rolling investigations. The application of the photo-rheological method to billet rolling needs experimental proof. Finally, the applicability of this experiment to metal rolling has not been demonstrated.

Extensive studies of celluloid as a photoplastic material for determining factors of stress concentration and strain distributions have been made by Fried (13), Frocht and Thompson (14); Frocht and Cheng (15), and Mönch and Loreck (16). Polycarbonate material was first suggested by Ito (17) while Gurtman, Jenkins and Tung (18), Brinson (19), and Whitfield (20) have shown the applicability of polycarbonate material in the study of elasto-plastic problems. Loreck (21) conducted studies of the mechanical and optical properties of polyestcr material to determine its applicability as a possible photoelastic material. Dally and Mulc (22) recently made an indepth study of polycarbonate as a model material for threedimensional photo-plasticity and established the strain-optic law relating the permanent plastic strains to the observed optical respone.

In all of these previous studies attempts were made to 
apply the principles of photoelasticity to studies of plastic deformation in small zones of a specimen in regions of high stress concentration (23). Design of such components is usually based on theory of elasticity considerations. A major difficulty always encountered when attempting to obtain stress or strain information by photoplastic methods is the selection of a model material which has stressstrain characteristics that simulate the real material. Several of the model materials mentioned previously were satisfactory on the limited scales required by the problems which were solved. Since these tests were usualiy in twodimensions and involved only limited plastic deformations, they do not appear to provide much insight into the phenomena associated with gross plastic deformation of the type encountered in forming operations.

Recently, Morris, and Riley (24) developed a photomechanic material which appeared to be well suited for studies beyond the elastic limit. The material, by trade name Laminac, is available in both flexible (Laminac EPX-126-3) and rigid (Laminac 4116) polyester resins. A cast of a 60:40 mixture of flexible and rigid resins provided a stress-strain curve that exhibited little or no strain hardening. From their studies they found that this material satisfied the requirements listed by Frocht and Thomson (14) for the transi- : tion from model to reál material in plane elasto-plastic 
problems. Among these requirements, three of which are weil understood, are:

a) model and real materials must have the same shape of stress-strain curve

b) the law of yielding must be the same for both materials

c) the value of Poisson's ratio in the plastic range must be the same for both materials.

The material must also meet the following requirements which are listed in the experimental stress analysis textbook by Dally and Riley (7):

a) visible light transparency

b) sensitivity to either stress or strain, as indicated by a low material fringe value in terms of either stress, $f_{\sigma}$ or strain, $f_{\varepsilon}$

c) isotropy

d) homogeneity

e) nonexcessive creeping

f) high modulus of elasticity

g) high ultimate strength

h) material sensitivity ( $f_{\sigma}$ or $f_{\varepsilon}$ ) should not change markedly with small variations in temperature

i) no time-edge effects caused by absorption of water vapor

j) machinability

k) no residual stresses

1) material should not be prohibitively expensive 
Nondimensional stress-strain comparisons for aluminum and the 60:40 mixture of Laminac polyester resins under uniaxial tension are shown in Figure 1.

In order to compare the stress-strain behavior of different materials, the Ramberg-Osgood (25) relation is employed. This relation allows the use of dimensionless variables indicated in Figure 1.

The Ramberg-osgood relation is

$$
\frac{E \varepsilon}{\sigma_{1}}=\frac{\sigma}{\sigma_{1}}+3 / 7\left(\frac{\sigma}{\sigma_{1}}\right)^{n}
$$

where $\mathrm{E}$ is Young's modulus, $\sigma_{1}$ is a secant yield stress determined by a secant modulus, $E_{S}=0.7 \mathrm{E}, \sigma$ is the true stress, $\varepsilon$ is true strain, and $n$ is a parameter chosen to provide the best fit to the stress-strain curve of the actual material being considered and is computed from the expression

$$
\mathrm{n}=1+\frac{0.3853}{\log _{10} \frac{\sigma_{1}}{\sigma_{2}}}
$$

where $\sigma_{2}$ corresponds to a second secant modulus, $0.85 \mathrm{E}$.

The curves in Fig. 1 indicate that the 60:40 polyester mixture can be used to simulate the behavior of aluminum under hot working conditions.

Until the present time, all the theories of hot rolling have been based on the various assumptions mentioned earlier. 
That these assumptions are not always valid can be demonstrated, for example, by the fact that defects such as doubleedge bulging, edge cracks and other defects which are not predicted by the theories appear during hot rolling of aluminum and other materials in commercial practice. Such problems stem from secondary stresses produced by the distribution of internal strains. Unfortunately, the distribution of internal strains is generally not known nor is the variation of the internal strain distribution known with respect to factors such as; work-roll diameter, reduction per pass, initial thickness of the work-piece, speed of rolling, front and back tension, nature of friction between the rolls and the material rolled, temperature field in the material, physical properties of the material, shape of the roll contour and the mill behavior under load.

The main purpose of this research, therefore, was to start with the Laminac material described above and improve on it in order to develop a material suitable for simulating the three-dimensional strain distributions in hot rolled aluminum. A clear understanding of the strain distribution should provide clues to the solution of the practical problems that are being encountered. 


\section{EXPERIMENTAL PROCEDURE}

Flexible (Laminac EPX-126-3) and rigid (Laminac 4116) resins were blended with one percent ethyl ketone peroxide and thoroughly mixed. The mixture was cast into a rectangular aluminum mold whose inner surfaces had been sprayed with a mold release agent to enhance the removal of the cast after curing. The cast was allowed to partially cure by holding at room temperature for 24 hours. The partially cured block was then removed from the mold, hung in an oven, post-cured at $80^{\circ} \mathrm{C}$ for 16 hours and then machined to give a smooth surface. (During machining care must be taken that stresses are not introduced as a result of clamping.)

\section{Compression of Rectangular Blocks}

Rectangular blocks $1 / 4$ inch thick, $1 / 2$ inch wide and $3 / 4$ inch high, for the determination of the fringe material values, were compressed in a hand operated hydraulic loading frame of the type commonly used in photoelastic polariscopes.

Compression of Cylindrical Samples

Cylindrical samples of the $60 \%$ flexible resin and $40 \%$ rigid resin mixture 0.35 inch in diameter by 0.5 inch height were compressed at room temperature in a screw driven Instron Tensile machine (Model T.T.C. with compression 
adaptor) at a strain rate of $0.004 \mathrm{~min}^{-1}$ to determine the true stress-strain behavior of the mixture.

Since the purpose of the research is to develop a material to simulate the strain distributions of hot rolied aluminum billets, cylindrical samples of the 60:40 mixture with the same geometry as those compressed at room temperature, were compressed in a mineral oil bath at temperatures ranging from $30^{\circ} \mathrm{C}$ to $50^{\circ} \mathrm{C}$. The compressions were at strain rates of $0.1,0.2,0.4$ and $1.0 \mathrm{~min}^{-1}$. Six aluminum samples of the same geometry were also compressed at temperatures of $300^{\circ} \mathrm{C}, 425^{\circ} \mathrm{C}$ and $500^{\circ} \mathrm{C}$ which correspond to the low, middle and high side of the commercial rolling temperature range for aluminum. At each temperature two samples were compressed at strain rates of 0.1 and $0.2 \mathrm{~min}^{-1}$. Machine deflection was determined for each of these temperatures at a crosshead rate of $0.002 \mathrm{in} / \mathrm{min}$ in order to correct the loadelongation charts so that only specimen length changes were used in calculating true stress-strain curves of aluminum at these temperatures.

The comparison of the true stress-strain curves of the cylindrical samples of the 60-40 mixture compressed at temperaturcs from $30^{\circ} \mathrm{C}$ to $50^{\circ} \mathrm{C}$ with those for the aluminum samples compressed at $300^{\circ} \mathrm{C}, 425^{\circ} \mathrm{C}$ and $500^{\circ} \mathrm{C}$, will help in determining whether the 60-40 mixture can be used to simulate the strain distribution in hot rolled aluminum billets. 
Compression of Discs

The governing equation in photoplasticity is of the form $\left(\varepsilon_{1}-\varepsilon_{2}\right)=\frac{\mathrm{Nf}}{\mathrm{h}}$ where $\left(\varepsilon_{1}-\varepsilon_{2}\right)$ is the difference between the larger and smaller in-plane principal strains, $f_{\varepsilon}$ is the material calibration constant, $\mathrm{N}$ is the photoplastic fringe value and $h$ is the thickness of the specimen in the direction of viewing. To obtain quantitative data for a photoplastic material, it is necessary to determine the magnitude of the material calibration constant, $f_{\varepsilon}$ ' used in the governing equation. To do this, a disc of 1.25 inch diameter and $3 / 8$ inch thick was cut from the cast block of material. It was vapor coated on one face with aluminum after which a fine line grille was etched into the coating. This provided a relatively coarse Moire grille of good contrast so that while the disc was being compressed diametrically, to a maximum reduction in height of $20 \%$, both Moire and photoplastic fringes could be observed simultaneously. The fringes were carefully watched to determine whether they would display the trend noticed by Morris and Riley (24) whereby the fringe order $\mathrm{N}$ increased up to a certain level and then decreased while the load was increased steadily as shown in Figure 2 . In the tests reported in this thesis there was, fortunately, no such decrease even up to a reduction of $20 \%$. This shows 
that the material behaved differently in uniaxial compression from that reported by Morris and Riley and it was concluded that the Moire method could be successfully used to establish the photoplastic material constant $\mathrm{f}_{\varepsilon}$.

Having established these facts; three discs of the 60:40 mixture were compressed to determine the value of the material fringe calibration factor, $\mathrm{f}_{\varepsilon}$. The discs had dimensions identical to those mentioned above but had diametrically opposite edges flattened to prevent rotation during loading.

To obtain a good Moire pattern a cross grid image of 200 lines per inch was transposed on to one face of each disc by using Kodak photo resist. Each disc was dipped into the resist and then withdrawn slowly and steadily at a rate of one inch per minute. This avoids wedging of the photosensitive coating and yields a smooth photosensitive base. The coated discs were then dried under an infra-red lamp for five minutes to prevent the grid negative from sticking to the surface of the discs. A negative of the grid was then laid on the surface of each disc, held down by plexiglass and exposed for two minutes under a mercury arc light source. Each disc was then held in Kodak photo resist developer under constant agitation for 2 minutes, washed in running water and allowed to dry completely. This produced a good Moire grid on one face of each disc. Finally the contrast of the grid 
was improved by dipping into a Kodak Photo Resist black dye. The result was an excellently adhering Moire grid with first class contrast.

With this cross grid of 200 dots per inch successfully transposed onto the surface of the disc (specimen grid), the Moire method for strain analysis could be employed. A line grille of 200 lines per inch was used as the reference or master: grille. Super-positioning of this line grille on the specimen grid gives rise to a family of Moire. fringes for displacements along one of the axes, while its rotation through $90^{\circ}$ gives rise to another set or family of fringes providing displacements along the other axis. Thus displacement measurements could be made in both $x$ and $y$ directions throughout the field of the disc.

Each disc was compressed diametrically in a mineral oil bath at $40^{\circ} \mathrm{C}$ with a cross-head speed of $0.1 \mathrm{in} / \mathrm{min}$. A 258 reduction was given to one disc, a $20 \%$ reduction to another and $a 15 \%$ reduction to the third disc. on attaining these strain levels, the load was removed immediately and each disc was allowed to cool in the oil bath to room temperature: As soon as room. temperature was reached the discs were removed from the bath, wiped dry and laid on an unexposed photographic film with the deformed grid in contact with the emulsion. Contact photographs of the deformed grid on each surface were taken by simple exposure to light. This was 
immediately followed by photographing the simultaneous photoplastic fringe pattern of each disc in white light and in monochromatic yellow light. With the deformed grid thus permanentiy recorded on film the reference grille could at any time be placed over the contact prints of the specimen grid such that it was aligned with one of the two orthogonal directions: Photographs of the resulting Moire fringes were taken; the reference grille was rotated $90^{\circ}$ over the contact prints of the specimen grid and a second set of Moire fringes were photographed. From these two sets of Moire fringes the values of the principal surface strains $\varepsilon_{1}$ and $\varepsilon_{2}$ at the center of each disc could be obtained. Putting these values into the strain optic equation, $\varepsilon_{1}-\varepsilon_{2}=\frac{N f}{h}$, allowed the material fringe value to be determined.

Roliing of the 60:40 Mixture

A $3 / 8$ inch thick by $1 / 2$ inch wide sheet of the $60: 40$ Laminac mixture was rolled at room temperature in order to compare the fringe pattern obtained in uniaxial compression with one obtained by rolling. Additionally, two six inch long by one inch thick blocks were heated to $40^{\circ} \mathrm{C}$ in a constant temperature mineral oil bath and rolied in a mill whose rolls were preheated to $40^{\circ} \mathrm{C}$. The blocks were then put back in the oil bath and cooled to room temperature. Immediately after cooling they were sliced and studicd photoelastirally to 
obtain the fringe patterns in the planes of the slices. Photographic Materials and Methods

Al1 the isochromatic colored fringes were taken with a Nikon $F^{\prime}$ Photomic camera having a Micro-Mirror Auto $55 \mathrm{~mm}$ f/3.5 lens. The film used was high speed Ektachrome type B 135. Correct exposure was established by the build-in light meter. Bracketing exposures, one aperature stop under and two under, helped to record clearly the lighter fringes at the center of the compressed sample. A Nikon polarizing filter, which properly fit the camera, was used as the analyzer. A reflector photoflood lamp type CXC RFL-2 whose cone of illumination just covered the sample was used as the light source. The colored films were processed in Ektachrome E 4 .

Black and white photographs of Moire fringes were taken with a Linhof 4 x 55 view camera having a Schneider symmar. 1:5.6/150 mm lens. $4 \times 5 \mathrm{Tri} X \mathrm{X}$ pan professional and $4 \times 5$ polaroid Polar Pan type 52 films were used. The polaroid film was used to check the exposure time and the alignment of the polarizing filter. After exposure time and filter alignment were checked, fringe patterns in the samples were permanently recorded on the film. Films were processed in normally recommended developer and fixer. 
Kodalith ortho films were used to record the contact images of the grids on the sample after compression. A point light source was used to expose the film with the sample held in contact with the film by a piece of glass. Films were processed in an automatic film processor. 


\section{RESULTS \\ Compression of Rectangular Blocks}

Rectangular blocks of various sizes were compressed as illustrated by the sketch in Figure 3a. The first few compressions of $10 \%$ reduction indicated that the intended reduction was not maintained after the material was unloaded. Upon giving the material a $20 \%$ reduction followed by unloading and allowing the material to creep relax an 8-12\% reduction was attained.

Compression of small (2" $x 13 / 4 " \times 3 / 4 ")$ rectangular blocks produced double bulge fringe patterns at both ends of the surface sections and a tendency towards a uniform field in the mid-section of the specimens (Figure $3 b$ ).

To improve optical, resolution a larger $\left(2^{\prime \prime} \times 13 / 4 " x\right.$ 2") model was compressed. The fringe patterns developed in blocks of two different heights are shown in Figure 4 . Interpretation of these monochromatic (black and white) fringes is difficult since the direction of increasing fringe order is not known. Colored photographs of the fringe pattern in samples exposed to white light contain this information but, because of consecutive elimination of light bands of dif-. ferent wave length, information from colored photographs are limited to fringe orders below six Figure 5 .

A color photograph of the fringe pattern shown in black 
and white in Figure 4 gave no helpful information because the fringes were of too high an order and could not be resolved. Since the fringe order $\mathrm{N}$ is proportional to the thickness $\mathrm{h}$ of the model, the fringe order could be reduced and sensible information would be obtained by slicing the model as shown in Figure 6 . Both the front and back slices ( 1 and 3 ) exhibited a double-bulge fringe pattern at the ends but the middle slice (2) did not. The qualitative results are shown in the color prints of Figure 7 . The corresponding fringe order, $\mathrm{N}$, (i.e., the strain distribution) of each slice is sketched qualitatively in Figure 8. The results leading to the sketch in Figure 8 clearly demonstrate one very powerful advantage of the model material; a specimen can be plastically deformed and the strains will be temporarily frozen into the specimen. By cutting at various planes a full three-dimensional analysis of the Eringes is possible throughout the body.

\section{Compression of Cylinarical Samples}

True stress-true strain curves of the 60:40 mixture obtained by compressing cylindrical samples at different strain rates in an oil bath at $40^{\circ} \mathrm{C}$ correlated very well with the true stress-true strain curves of identically shaped aluminum cylinders compressed at temperatures of $300^{\circ} \mathrm{C}, 425^{\circ} \mathrm{C}$ and $500^{\circ} \mathrm{C}$ 
(Figure 9). At temperatures above $40^{\circ} \mathrm{C}$ the true stress-true strain curves of the Laminac mixture did not correlate with those of aluminum at 300 to $500^{\circ} \mathrm{C}$. This is because the modulus of the model material decreases abruptly at temperatures between $40^{\circ}$ and $50^{\circ} \mathrm{C}$. As a result the shape of the true stress-true strain curves change drastically.

Compression of Discs at $40^{\circ} \mathrm{C}$

Figure loa shows the Moire fringes produced as a result of superimposing a 200 line per inch line grid over the grid of the specimen given a $25 \%$ reduction. With this relative orientation of the grids, the strain in the $y$ direction at any point in the disc can be determined as illustrated in the Appendix. Figure lob shows another family of Moire fringes obtained by rotating the reference grid through $90^{\circ}$. In this orientation, the strain in the $x$ direction can be determined. In particular the strains in the $x$ and $y$ directions at the center of the discs were evaluated. The strain values corresponding to 15,20 and $25 \%$ reduction in diameter across the flat's are given in Table 1.

Figure 10c shows the photoplasticity fringes of the strain field assoriated with the same disc. Highly accurate counts of fringe order, $N$, were obtained from all three compressed discs as soon as they had cooled to room temperature by taking isochromatic fringe patterns in the narrow band 
yellow light of a low pressure sodium light source in a diffuse light polariscope. With the polariscope elements aligned so that the background had a light field, interference fringes occurred at half-order fringe counts. For an arrangement which gave a dark background, interference fringes occurred at whole number fringe counts. Such "dark field" and "light field" isochromatic fringe pattern are shown in Figure lla and Figure 11b; respectively. From the photoplasticity fringe pattern, the fringe order, $N$, was obtained at the center of the disc. Values are given in Table 1 .

Figure lod shows the zero degree isoclinics of the compressed disc, i.e. wherever the disc is black the principal strains in the plane of the disc were in the vertical $y$, and horizontal $\mathrm{x}$ directions.

Table i. Values used to obtain the fringe constant, $f_{\varepsilon}$

\begin{tabular}{ccccc}
\hline $\begin{array}{l}\text { Reduction in } \\
\text { Diameter, } 8\end{array}$ & $\varepsilon_{x^{\prime}} 8$ & $\varepsilon_{y^{\prime}} \frac{8}{8}$ & $\mathrm{~N}$ & $f_{\varepsilon}$ in/in/fringe \\
\hline 15 & 4.18 & -4.90 & 7.50 & $0.005 \pm 88$ \\
20 & 7.20 & -9.97 & 12.00 & $0.005 \pm 88$ \\
25 & 12.78 & -19.33 & 25.50 & $0.005 \pm 88$ \\
\hline
\end{tabular}


Rolling of the 60:40 Mixture

Rolling a $3 / 8$ inch thick sheet of the 60:40 mixture at room temperature gave a fringe pattern (Figure 12) similar to one obtained by uniaxially compressing a rectangular block, Figure 3b.

The two blocks. which were rolled at $40^{\circ} \mathrm{C}$ were sliced as follows. Three slices were taken longitudinally from one block as shown in Figure $13 a$ and another set of three slices was taken transversely from the second block, Figure 13b. To a first approximation, the color fringes at position $A-A$ in the planes of the three longitudinal slices, Figure 14a, show that the strain in the center slice is less than in the remaining two slices. This is evident from the fact that the green color is much fainter in the center slice than in the other two slices. The fringe order $N$, i.e., the strain distribution along position $A-A$ in $F$ igure $14 \mathrm{a}$ is represented qualitatively for all three slices by the sketches in Figures $14 \mathrm{~b}$ and $14 \mathrm{C}$.

Due to the fact that each of the blocks was tapered at one end in order to get the rolling started, the transverse slice taken around the tapered region of the block did not show any fringes since this region was not deformed. The transverse slice at the top of Figure 15a corresponds to the slice taken transversely from the tapered region. The center 
and lower transverse slices in Figure $15 a$ did have fringes since the block was deformed plastically as a result of rolling.

The fringe pattern corresponding to position s-s or $S^{\prime}-S^{\prime}$ on either the center or lower transverse slice, as shown in Figure 15a, revealed double bulging similar to that which had occurred in the rectangular block compressed uniaxially (Figure $3 a$ ). This phenomenon of double bulging is also observed in hot rolled aluminum billets. The fringe order $\mathrm{N}$, (i.e. the strain distribution) corresponding to position $S-S$ or $S^{\prime}-S^{\prime}$ on the central or lower transverse slice in Figure 15a, is sketched qualitatively in Figure $15 b$.

The fringe pattern corresponding to position.B-B on the center transverse slice of Figure $15 \mathrm{a}$ or position $\mathrm{C}-\mathrm{C}$ on the lower transverse slice, revealed the strain distribution illustrated qualitatively in Figure 15c. It is evident that the strains have minimum values at the edge and center of the rolled piece, consistent with the minima of Figure 15b. The strains increase to maxima midway between edge and center of the work piece such that a saddle position occurs at the center of the slice.

Thus it can be concluded that strain distributions are similar for uniaxially compressed or rolled material as long 
as the height to width ratios are equivalent. This observation confirms a suggestion made by Mican (26). 


\section{DISCUSSION}

As indicated earlier in this thesis, the objective of the research was to develop and characterize a photoplastic modeling material which would permit the three-dimensional strain distributions associated with hot formed parts to be described.

Based on the work of Morris and Riley (24), a $60: 40$ mixture of flexible and rigid resins appeared to be a suitable material for modeling aluminum, at least in tensile loading situations. Consequently; this material was chosen as a sensible starting point for developing a suitable modeling material for the hot forming of aluminum. It remains to demonstrate whether the same material will model satisfactorily other metals during hot forming.

Since hot forming operations involve compressive loading primarily, it was necessary first to determine the birefringence characteristics of the 60:40 mixture in compression at room temperature.

Despite the fact that the rate of loading in a hand operated hydraulic loading frame of the type commonly used in photoelastic polariscopes could not be controlled, the compression of the smaller rectangular blocks of 60:40 Laminac. mixture at room temperature produced double-bulge fringe patterns at both ends of surface sections and a tendency 
towards a uniform field in the mid-section of the specimen. The front and back slices taken from larger rectangular blocks compressed at room temperature exhibited doublebulge fringe pattern at the ends (Figure 7 ). The $3 / 8$ inch thick sheet of the 60:40 Laminac mixture which was rolled at room temperature also exhibited a double-bulge fringe pattern (Figure 12). This shows that whether the 60:40 Laminac mixture is rolled or compressed the same result still prevails. This double-bulge has also been observed on the edges of hot rolled aluminum billets.

During the course of the room temperature studies it was learned that strain rates at as low as $0.05 \mathrm{~min}^{-1}$ caused the 60:40 mixture to respond in a brittle manner. Despite the favorable simulation characteristics of this potential modeling material at strain rates of the order $0.005 \mathrm{~min}^{-1}$ or lower, the brittle response at slightly higher strain rates limits its utility for forming process simulation because the latter involve much higher strain rates. Furthermore, the pace of an experimental program is severely constrained by the required low test rates. For this reason, it was decided to investigate other:mixtures of the rigid and flexible resins as well as other materials that might exhibit good simulation characteristics at strain rates higher than those allowed by the 60:40 mixture at room temperature.

Two mixtures of the rigid and flexible resins, 70 
flexible: 30 rigid and 80 flexible: 20 rigid, and a polycarbonate, Lexan, were chosen for this effort. Cylindrical samples of these materials having the same dimensions as the 60:40 compression test samples were compressed at room temperature at strain rates of $0.02,0.1,0.2,0.4$ and 1.0 min $^{-1}$. Although higher strain rates were possible without fracturing these materials, their.load-elongation curves were totally different than the load-elongation curves of compressed aluminum.

A second approach to achieve the goal of a modeling material. that would simulate hot aluminum at higher strain rates was attempted. This approach involved heating. the 60:40 mixture to higher temperatures. After some exploratory investigation, a temperature of $40^{\circ} \mathrm{C}$ was deemed most suitable. Lower temperature compression tests at moderate strain ratés did not simulate aluminum compression tests. Higher. temperatures cannot be employed because the Young's modulus of the 60:40 Laminac mixture changes drastically at temperatures between $40^{\circ} \mathrm{C}$ and $50^{\circ} \mathrm{C}$ thereby altering its stressstrain characteristics excessively.

The 60:40 Laminac mixture satisfied the requirement that the model and the real material must have the same shape of stress-strain curve. The true stress-true strain curves of cylindrical samples of 60:40 Laminac mixture obtained by compression at different strain rates in an oil 
bath at $40^{\circ} \mathrm{C}$ correlated very well with the true stress-true strain curves of identical aluminum cylinders compressed at temperatures of $300^{\circ} \mathrm{C}, 425^{\circ} \mathrm{C}$ and $500^{\circ} \mathrm{C}$. The stress-strain curves of aluminum compressed at $300^{\circ} \mathrm{C}, 425^{\circ} \mathrm{C}$ and $500^{\circ} \mathrm{C}$ and of the 60:40 Laminac mixture compressed at $40^{\circ} \mathrm{C}$, plotted according to the Ramberg-Osgood (25) relation (Figure 22), indicate that the 60:40 Laminac mixture does simulate the behavior of aluminum in hot compression.

The strain distributions in the longitudinal slices Figure $14 \mathrm{a}$ and in the transverse slices Figure 15a of the block of $60: 40$ Laminac mixture rolled at $40^{\circ} \mathrm{C}$ have been determined and sketched in Figure 14b, Figure 15b and Figure 15c. The fringe pattern in the transverse slices again displayed the double-bulge phenomenon. The resulting strain distributions are only qualitative because the rolling was not uniform. This is evident from the isoclinics (Figure 16) of the longitudinal slices of the rolled block. For steady rolling, the whole slices should be completely dark without any white spots.

Despite the fact that the 60:40. Laminac mixture at $40^{\circ} \mathrm{C}$ was found to simulate the uniaxial compression characteristic of hot aluminum and the fact that it can be rolled at $40^{\circ} \mathrm{C}$ in a qualitative simulation of aluminum, there remain several factors which deserve comment or further evaluation. Although the 60:40 Laminac mixture responded sensibly 
to strain, it is unfortunately visco-elastic, that is the strains relax slowly with time. This effect is evident in Figure 17. Figure 17a shows the fringe pattern of a disc under load while Figure $17 \mathrm{~b}$ shows the same disc two hours after the load was removed. Figure 17c shows the fringe pattern six days later. The extent of the relaxation is evident. Fortunately the rate of relaxation became much less when the disc was compressed at $40^{\circ} \mathrm{C}$ and allowed to cool in an oil bath to room temperature: Figure 18a shows the fringe pattern after the disc had been left in the oil bath for one hour to cool to room temperature and Figure $18 \mathrm{~b}$ shows the fringe pattern for the same disc six days later. Comparison of the two fringe patterns taken after six days (Figures $17 \mathrm{c}$ and $18 \mathrm{~b}$ ) shows that the rate of relaxation of the disc which was compressed at $40^{\circ} \mathrm{C}$ was slower than for the one which was compressed at room temperature i.e., the residual strain retained after six days was more in the disc compressed at $40^{\circ} \mathrm{C}$ and cooled to room temperature than the disc compressed at room: temperature. This lower rate of relaxation permits more time for analysis of the fringe patterns and strains without introducing serious errors in the determination of the material fringe constant which in turn controls the determination of the strains and the fringe order $\mathrm{N}$.

The nonuniformity in rolling of the block of 60:40 
Laminac mixture at $40^{\circ} \mathrm{C}$ may be due to many factors. On one hand it may be due to the unsteady rolling, or it may be due to friction. At this stage of the research the friction characteristics are unknown. An understanding of the friction characteristics will indicate whether the nonuniformity in rolling was due to friction or to the manner in which the roliting was achieved.

Despite unknown friction characteristics and relaxation, within the scope of work done so far toward finding a good simulating material for hot rolled aluminum, the 60:40 mixture rolled or compressed at $40^{\circ} \mathrm{C}$ produced evidence that demonstrates its potentiality for this purpose. The phenomenon of double bulging which occurs on the edges of hot rolled aluminum billets was revealed by the fringe patterns from a cold compressed rectangular block, from a cold rolled sheet and a hot rolled block of the 60:40 Laminac model material. Furthermore, the true stress-true strain curves of cylinders of the 60:40 Laminac mixture compressed at $40^{\circ} \mathrm{C}$ and aluminum cylinders compressed at $30^{\circ} \mathrm{C}, 425^{\circ} \mathrm{C}$ and $500^{\circ} \mathrm{C}$ correlated very well. These are convincing facts suggesting that the mixture of $60 \%$ flexible and 408 rigid resins can be used to simulate the strain distribution in hot rolled aluminum billets.

Based on the results of this research, it is not unduly optimistic to suggest that the $60: 40$ mixture at $40^{\circ} \mathrm{C}$ will 
provide qualitative, if not quantitative, information about the effects of billet size on the formation of double bulges and edge cracks during hot rolling of aluminum in commercial practice. It seems reasonable to conjecture that the 60:40 Laminac mixture may in the same way be used to model the strain fields which are set up in certain extrusion processes. 


\section{SUMMARY}

A photomechanic material, Laminac, which is a mixture. of $60 \%$ flexible and $40 \%$ rigid resins has been shown to have potential as a modeling material to simulate the threedimensional strain distribution in hot-rolled aluminum. Photomechanic analysis revealed that the 60:40 Laminac mixture, when compressed or rolled at $40^{\circ} \mathrm{C}$, exhibited the phenomenon of double bulging which has been observed in hot-rolled aluminum billets.

The 60:40 Laminac mixture satisfied the requirement that model and real material must have the same shape of stress-strain curve. The true stress-true strain curves of cylindrical samples of 60:40 Laminac mixture obtained at different strain rates in an oil bath at $40^{\circ} \mathrm{C}$ correlated very well with the true stress-true strain curves of identical aluminum cylinders compressed at temperatures of $300^{\circ} \mathrm{C}$, $425^{\circ} \mathrm{C}$ and $500^{\circ} \mathrm{C}$ as illustrated by a Ramsberg-osgood plot (25). 


\section{REFERENCES}

1. El-Waziri, A. H. "An Up-to-Date Examination of Rolling Theory." Iron and Steel Engineer 40 (October 1963), $10,73-80$.

2. El-Kalay, A. K. E. H. A. and L. G. M. Sparling. "Factors Affecting Friction and Their Effect Upon Load, Torque and Spread in Hot Flat Rolling." "Journal of the Iron and Steel Institute 206 (Feb. 1968), 152-163.

3. Helmi, A. and J. M. Alexander. "Geometric Factors Affecting Spread in Hot Flat Rolling of Steel." Journal of the Iron and Steel Institute 206 (Nov. 1968), 11101117 .

4. Beese, J. A. "Ratio of Lateral Strain to Thickness Strain During Hot Rolling of Steel Slabs." Journal of the Iron and Steel Institute 210 (June 1972), 433-. 436 .

5. Averbach, B. L. "Plastic Deformation in the Rolling Process." "Journal of Metals, Transactions AIME 188 (Jan. 1950), 150-155.

6. Orowan, E. "The Calculation of Roll Pressure in Hot and Cold Flat Roliling." Proceedings Institute of Mechanical Engineers 150, (1943) 140-167.

7. Dally, J. W., and W. F. Riley. Experimental Stress Analysis. New York: McGraw-Hill Book Co., 1965.

8. Durelli, A. J., and W. F, Riley. Introduction to Fhotomechanics. Englewood Cliffs, N.J.: PrenticeHall, Inc., 1965.

9. Hetenyi, M. "A Study in Photoplasticity." U.S. Natl. Congress of App. Mech. Proc. 1 (1952), 499-502:

10. Fried, B., and N. H. Shoup. "A Study in Photoplasticity." U.S. Natl. Congress of App. Mech: Proc. 2 (1954), 477-483.

11. Brill, W. A. "Basic Studies in Photoplasticity." Ph.D. Thesis, Stanford, Cal., 1965. 
12. Ohashi Yoshio, and Tadashi, Nishitani. "Effects of Front Tension on Strip Rolling. Analyzed by Photorheological Method." Japan Society of Mechanical Engineers Bulletin, 14, No. 76 (1971), 1043-1049.

13. Fried, B. "Some Observations on Photoelastic Materials Stressed Beyond the Elastic Limit." Proceedings of the S.E.S.A. 8(2) (1951), 143-148.

14. Frocht, M. M., and F. A. Thomson. "Studies in Photoplasticity." Proc. U.S. Natl. Cong. Appl. Mech. 3 (1958), 533-540.

15. Frocht, M. M., and Y. F. Cheng. "An Experimental Study of the Laws of Double Refraction in the Plastic State in Cellulose Nitrate-Foundations for Three-Dimensional Photoplasticity." Pages 195-216 in M. M. Frocht, ed. Photoelasticity: Proc. of Int. Symposium on Photoelasticity, 1961. New York: Pergamon Press, 1963.

i6. Mönch, E., and R. Loreck. "A Study of the Accuracy and Limits of Application of Plane Photoplastic Experiments." Pages 169-184 in E. Mönch, ed. Photoelasticity: Proc. of Int. Symposium on Photoelasticity, 1961. New York: Pergamon Press, 1963.

17\% Ito, K. "Studies on Photoelasto-plastic Mechanics." Journal of the Science Research Institute, Tokyo 50 (1956), 19-28.

18. Gurtman, G. A., W. C. Jenkins, and T. K. Tung. "Characterization of a Birefringent Material for Use in Photoelasto-Plasticity." Douglas Rep. SM-47796, Jan. 1965.

19. Brinson, H. F. "An Interpretation of Inelastic Birefringence." Experimental Mechanics 11(10) (Oct. 1971), $467-471$.

20. Whitefield, J. K. "Characterization of Polycarbonate as a Photoelasto-Plastic Material.". Ph.D. Thesis, Virginia Polytechnic Institute, 1969.

21. Loreck, R. "Untersuchung von PolyestergieBharzen and Anderen Kunststoffen auf ihre Eigung also photoplastishes Modell-material." "Kunststoffe 52 (1962), 139-143. 
22. Dally, J.W., and A. Mulc: "Polycarbonate as a Model Material for Three-Dimensional Photoplasticity." Journal of Applied Mechanics Transactions of the ASME 40, Series E, No. 2 (June 1973), 600-605.

23. Durelli, A. J., and C. A. Sciammarella. "Elastoplastic Stress and Strain Distribution in a Finite Plate with a Circular Hole. Subjected to Undimensional Load." J. of Applied Mech. 30 (March 1963), 115-121..

24. Morris, D. H., and W. F. Riley. "A Photomechanics Material for Elasto-Plastic Stress Analysis." Exptl. Mech : 12 (1972), (1972), 10, 448-453.

25. Ramberg, W. , and W. R. Osgood. "Description of Stress-Strain Curves by Three Parameters." U.S. Natl. Advisory Committee for Aeronautics, Tech: Note 902 , 1943.

26. Mican, G. S. "Deformation in Rolling." Iron and Steel Engineer 24 (February 1949), 2, 53-67.

27. Brewster, D. "On the communication of the structure of doubly refractory crystals to glass etc. by mechanical compression and dilation." Phil. Trans. Roy. Soc. $(1816), 156-78$.

28. Neumann, F. E. Berichte Königl. Preuss. Pogg Ann. 54 (1841), 449-76. Original not available; cited in R. B. Heywood, Photoelasticity for Designers, Vol. 2. New York: Pergamon Press, 1969.

29. Maxwell, J. C. "On the equilibrium of elastic solids." Trans. Roy. Soc., Edinburgh 20 (1853), 87-120.

30. Theocaris, P. S. Moiré Fringes in Strain Analysis. Oxford: Pergamon Press, 1969. 


\section{ACKNOWLEDGMENTS}

It was a pleasure to work under the direction of Dr. T. E. Scott to whom I am indebted for many valuable discussions. I wish to thank Dr. C. P. Burger and Professor W. F. Riley for their interest and stimulating discussions and Dennis Sailsbury for his excellent photographic work. I am also indebted to the Aluminum Company of America for the grant to support this research. Finaliy, I deeply appreciate the suggestions and constructive criticisms of Mr. Robert E. Fanning of Alcoa Research Laboratories. 
APPENDIX A

Figures 


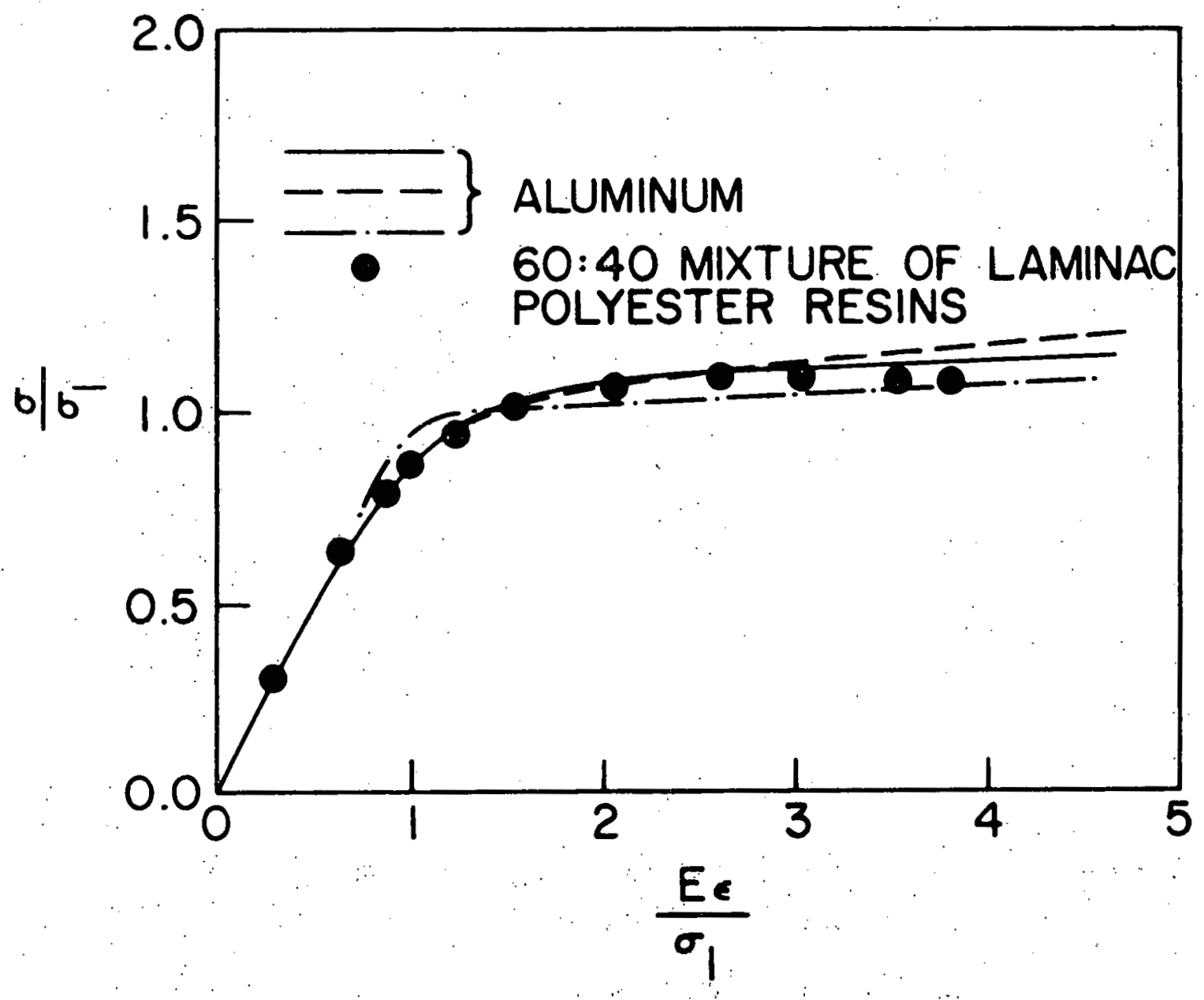

Figure 1. Comparison of stress-strain curves for aluminum and 60:40 Laminac mixture plotted according to Ramsberg-osgood relations 


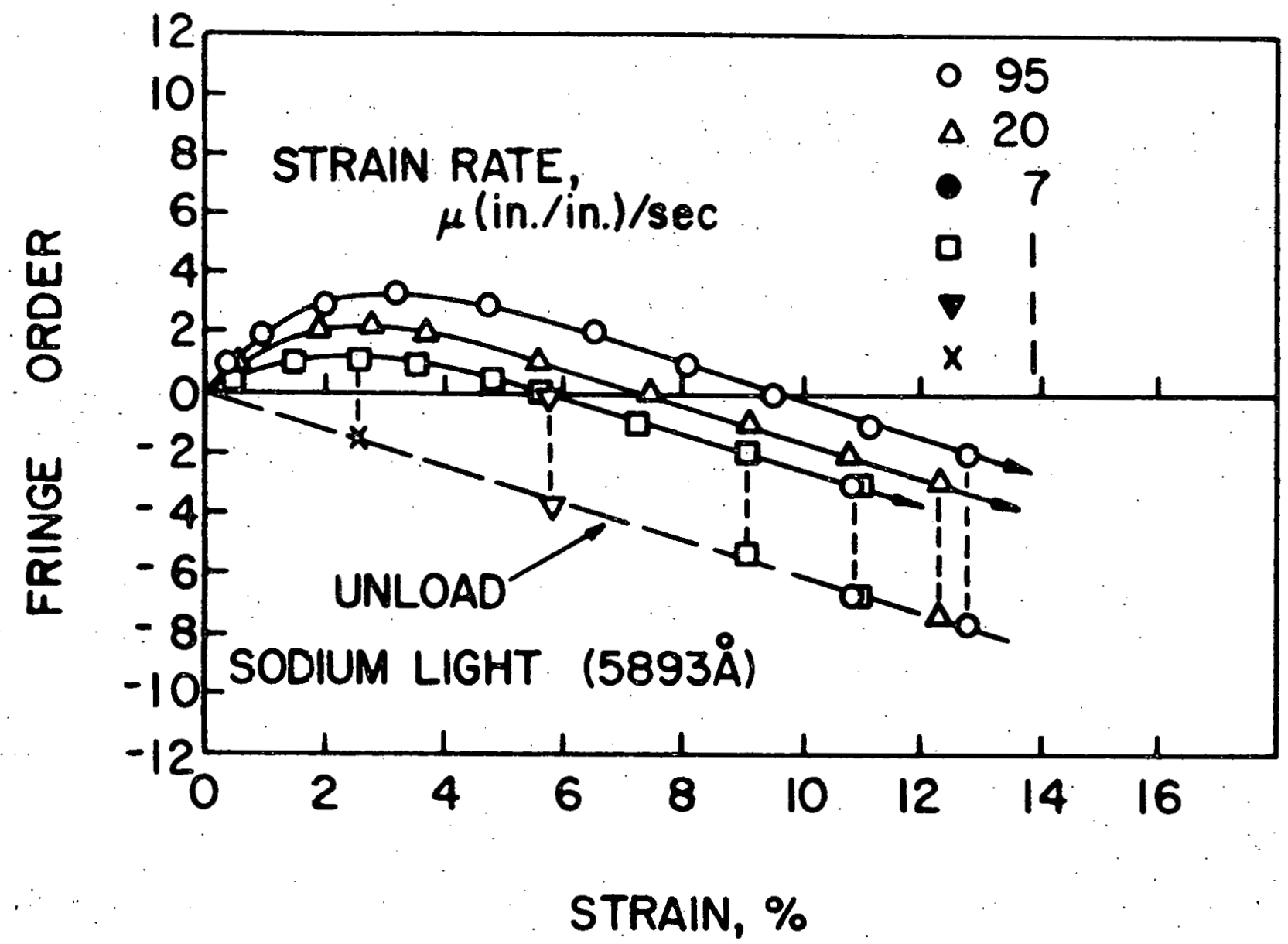

Figure 2. The strain dependence of birefringence at several strain-rates. Taken from reference (24) 


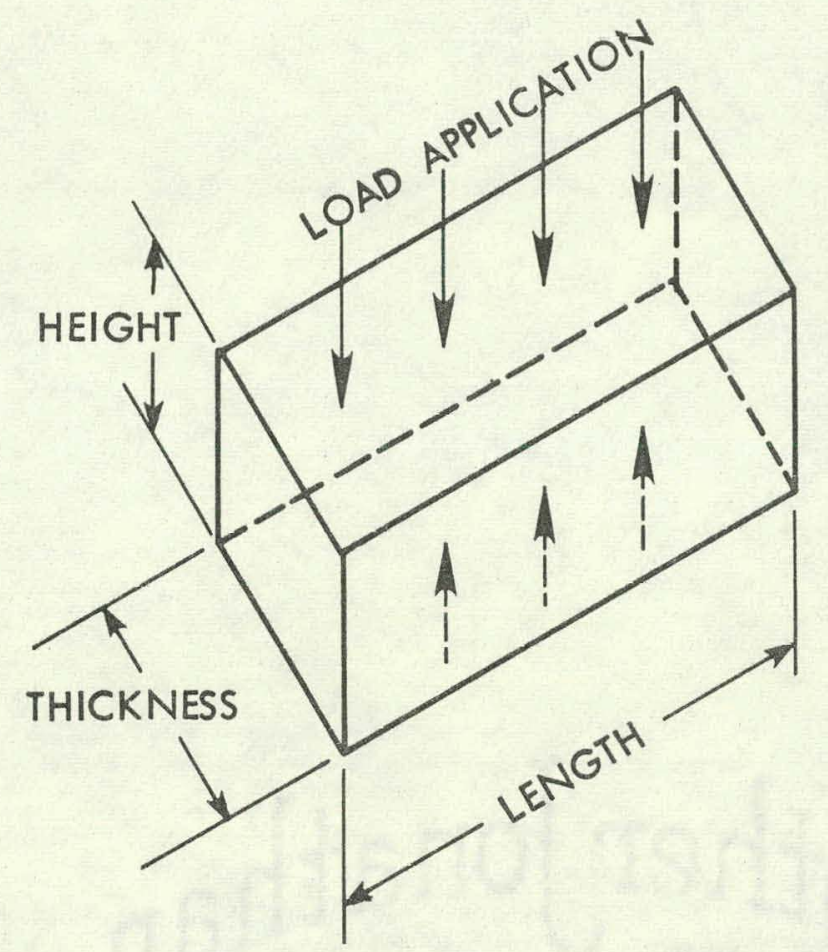

Figure 3a. Compression of rectangular blocks with varying length-to-height ratio

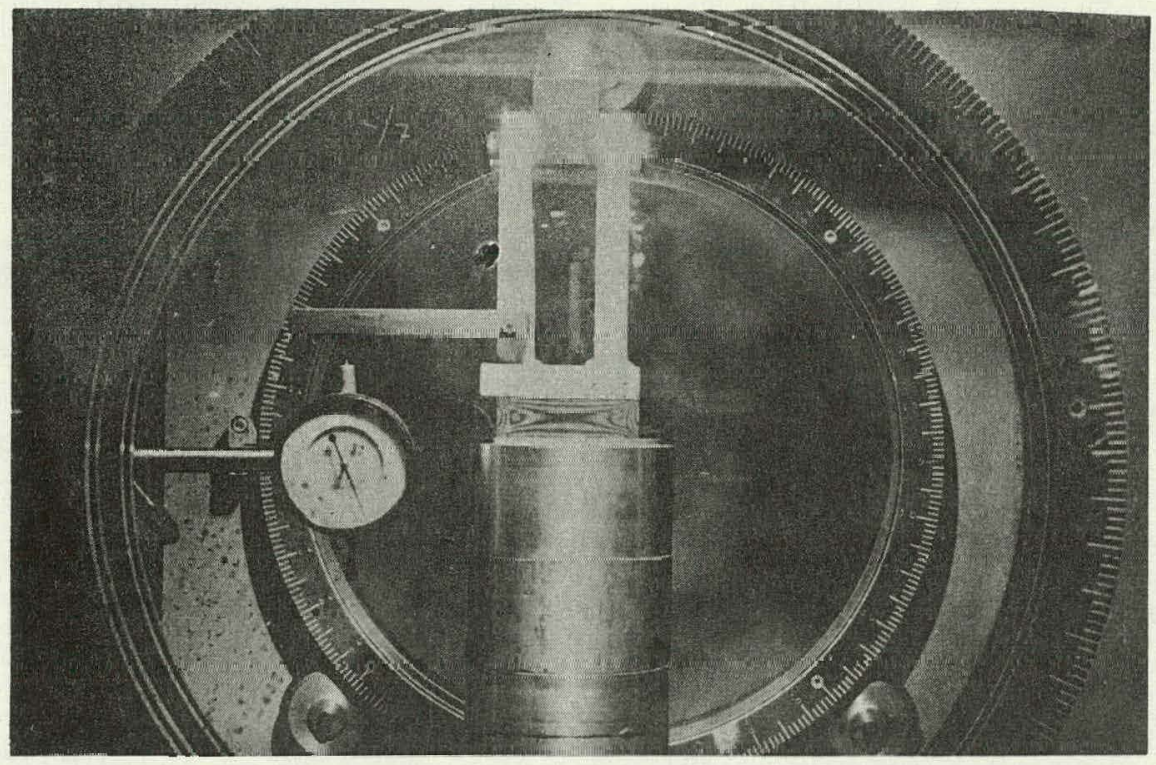

Figure 3b. Photograph of a specimen under load in the polariscope. Photoplasticity fringes can be seen quite clearly 

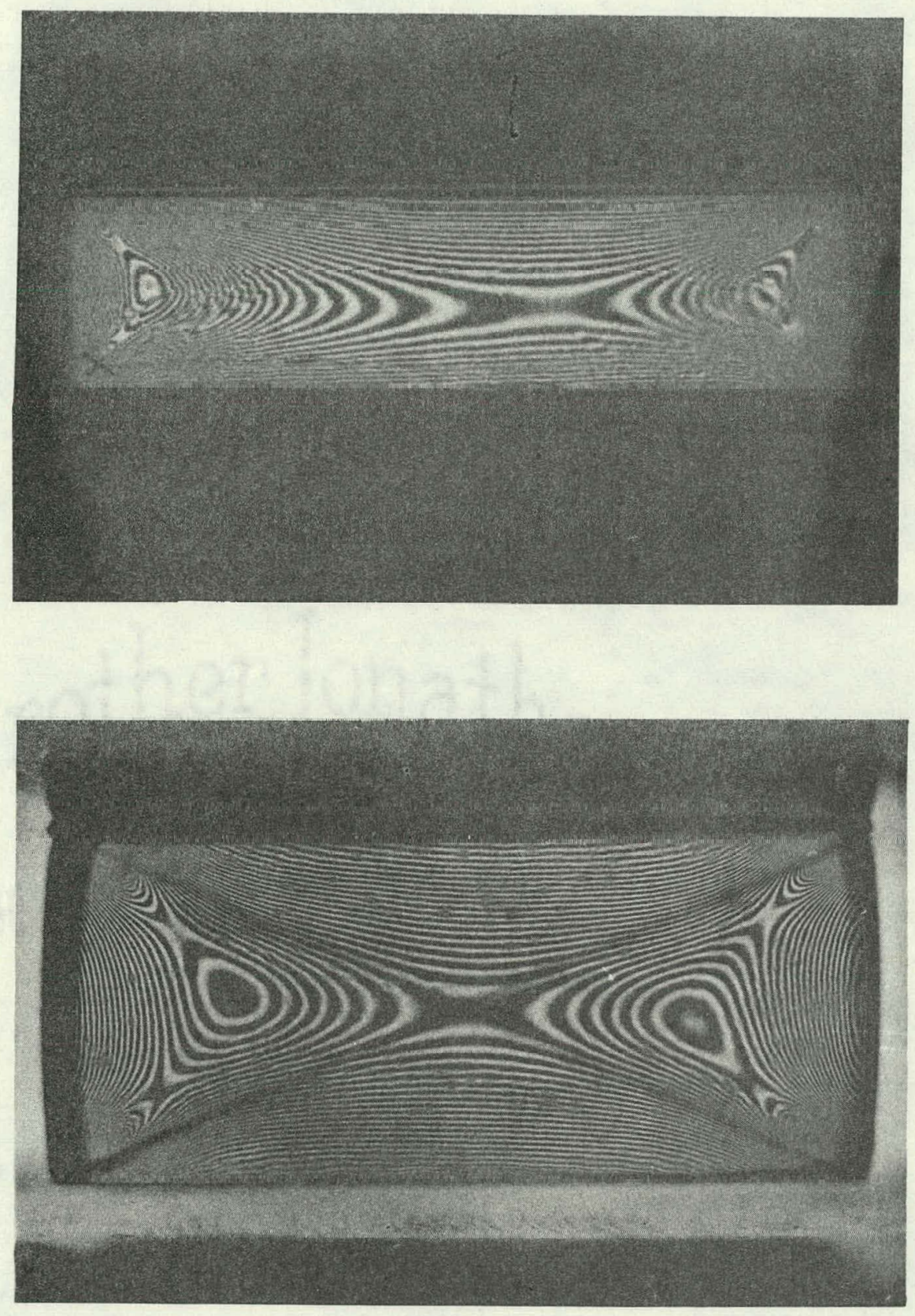

Figure 4. Black and white fringe patterns under monochromatic yellow light for two height-to-length ratios. Models are viewed through their full thickness 
Figure 5. Color photograph of a model illustrates tendency for high-order colored fringes to "wash out"

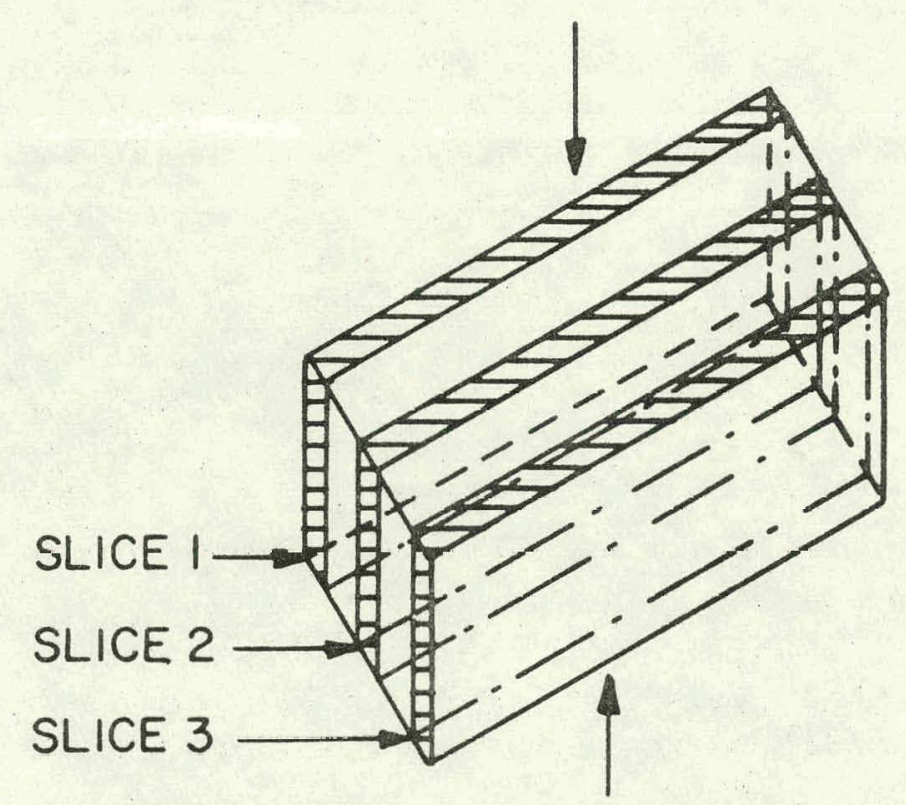

Figure 6. Sketch to show orientation of three slices taken from model to reduce the number of colored fringes and make them more clcarly visible 
Figure 7. Color photograph of slices taken from model. as shown in Figure 6 


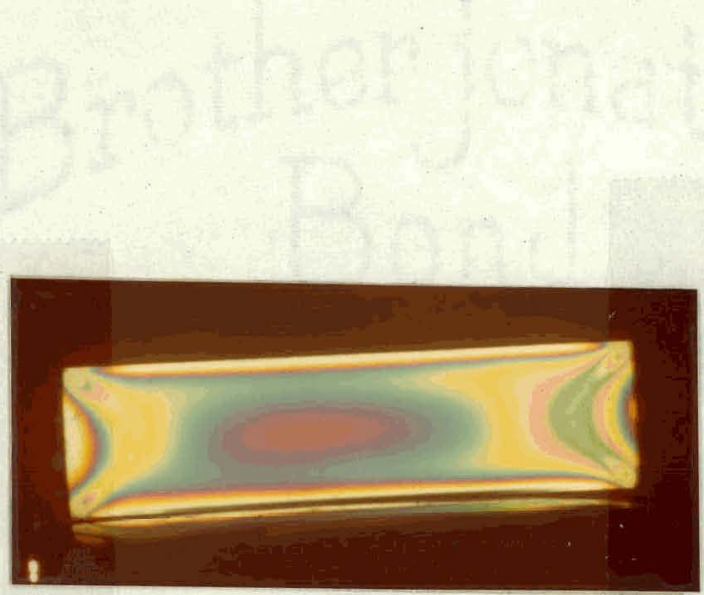

Slice 1

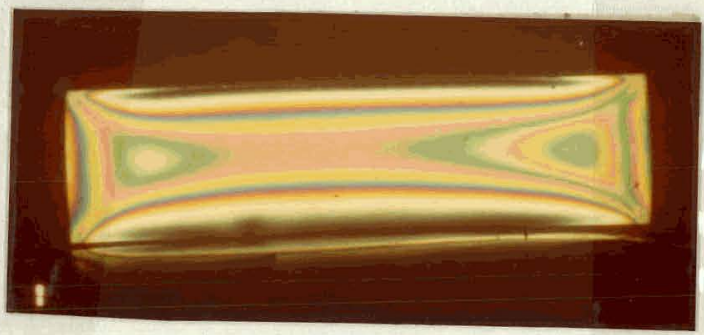

Slice 2

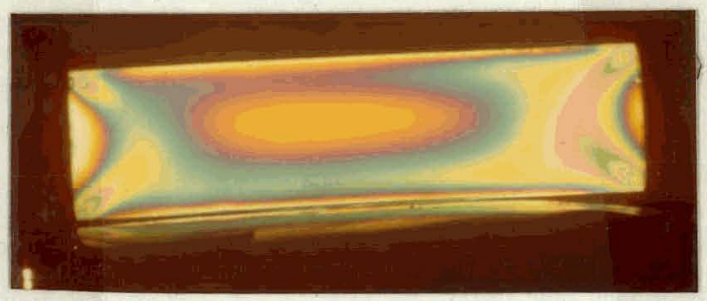

slice 3 
Photoplastic fringe values (N) along horizontal centerlines of three slices
Photoplastic fringe values

(N) along centerline and one edge of each of three slices
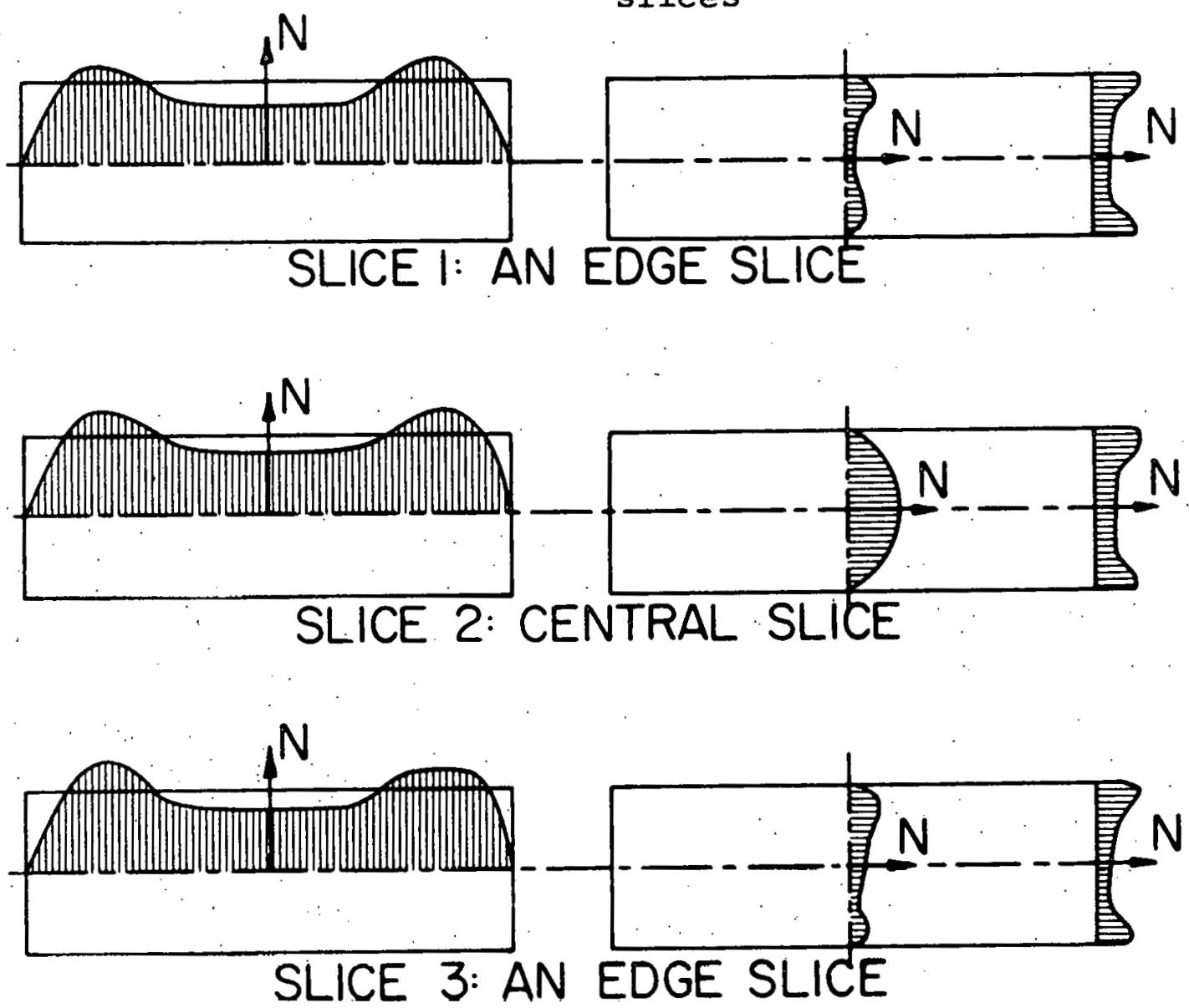

Figure 8. Plots of photoplastic fringe orders from slices cut as in Figure 5 and as photographed in Figure 6. Fringe value is proportional to strain as a first approximation 


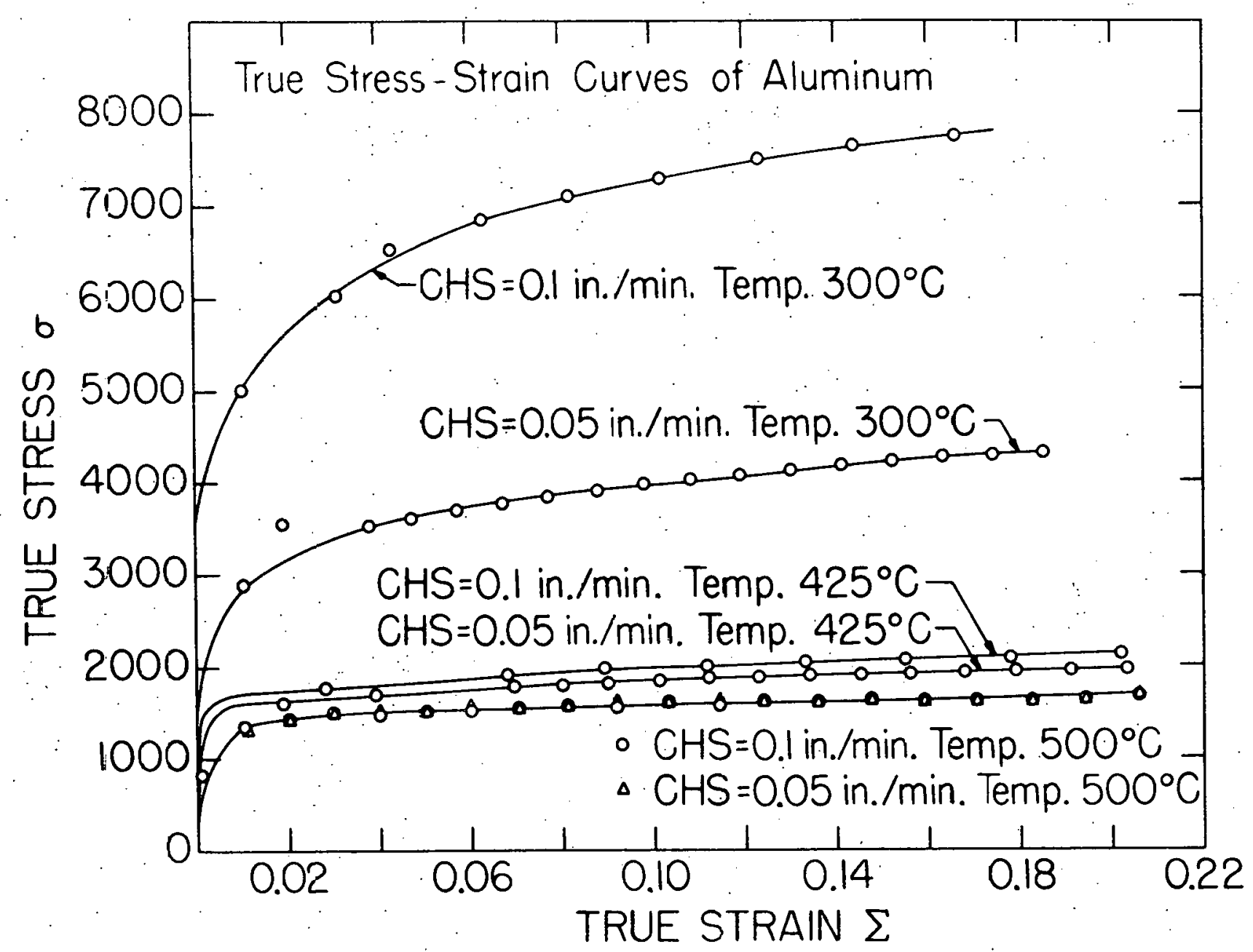

Figure 9a. True stress-true strain curves of aluminum at different temperatures and strain-rates 


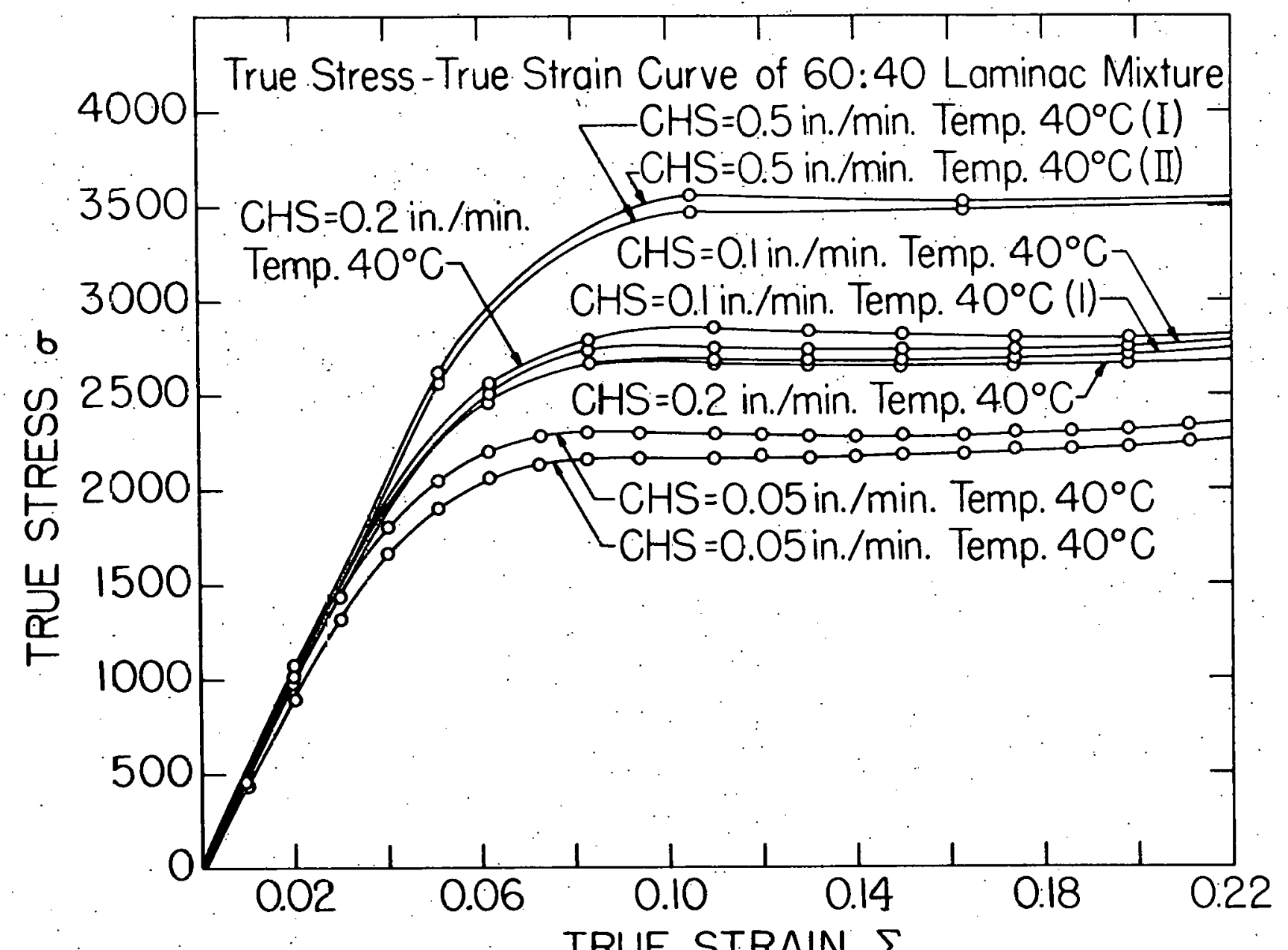

Figure 9b. True stress-true strain curves of 60:40 Laminac mixture at $40^{\circ} \mathrm{C}$ at several strain rates 

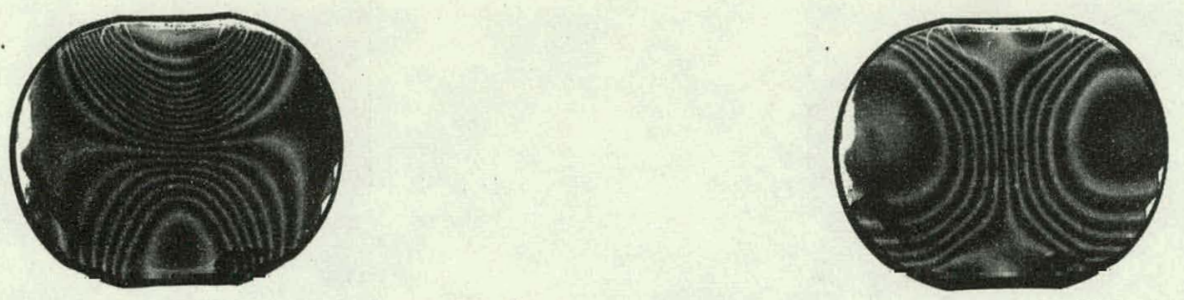

Figure 10a. Moiré of vertical strain field

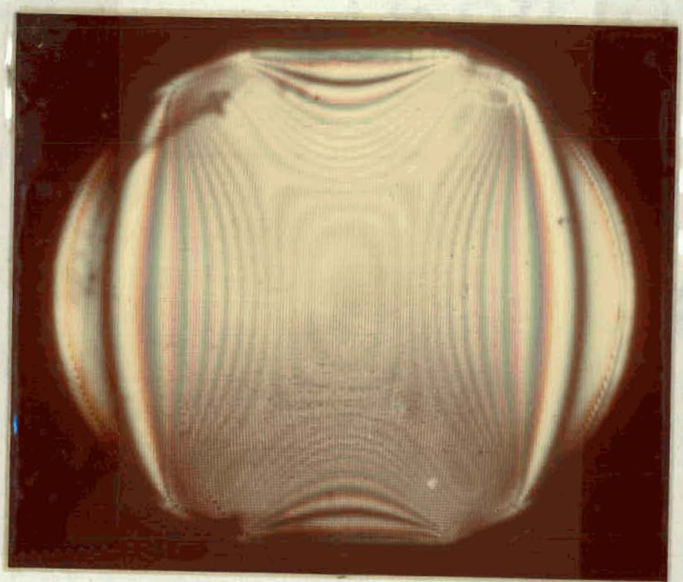

Figure 10c. Photoplasticity of the strain field
Figure 10b. Moiré of horizontal strain field

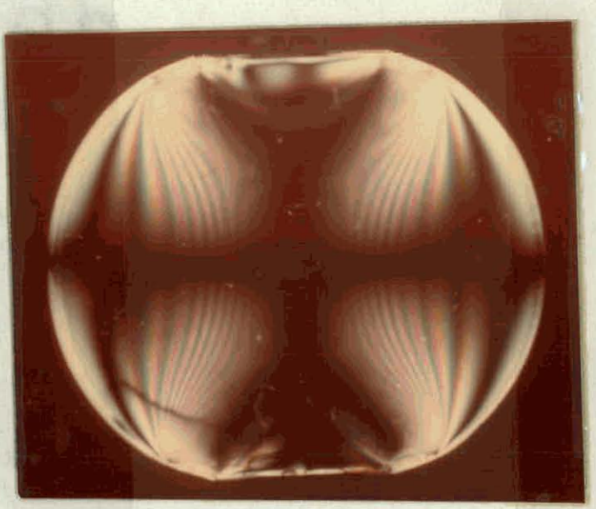

Figure 10d. Zero degree isoclinics of the compressed disc 


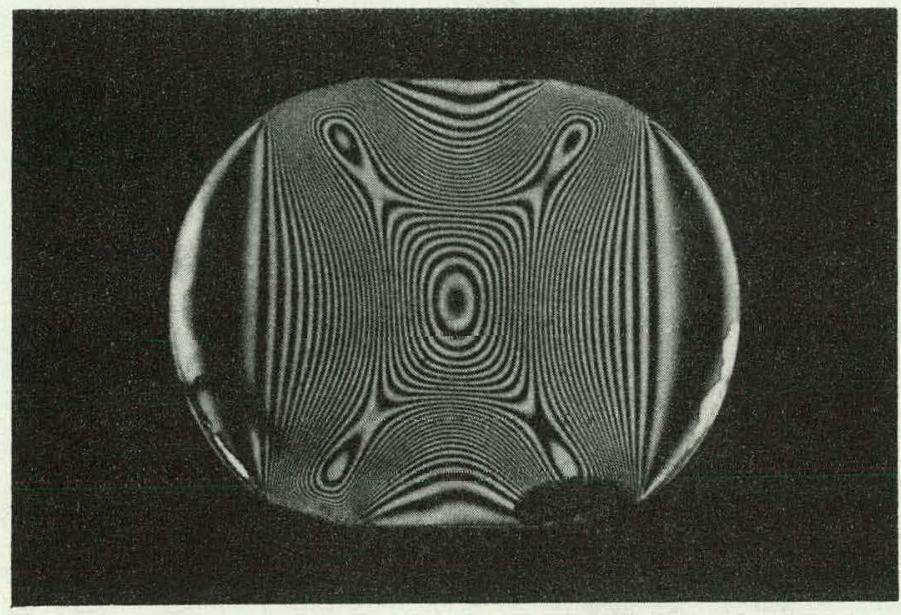

Figure 1la. Dark-field isochromatic fringe pattern of the disc loaded in diametral compression

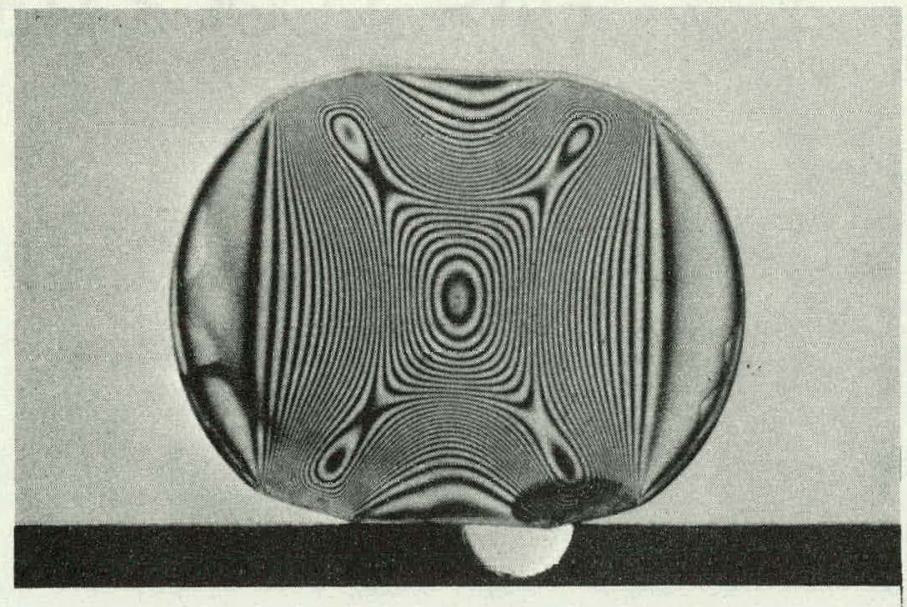

Figure 11b. Light-field isochromatic fringe pattern of the disc loaded in diametral compression 


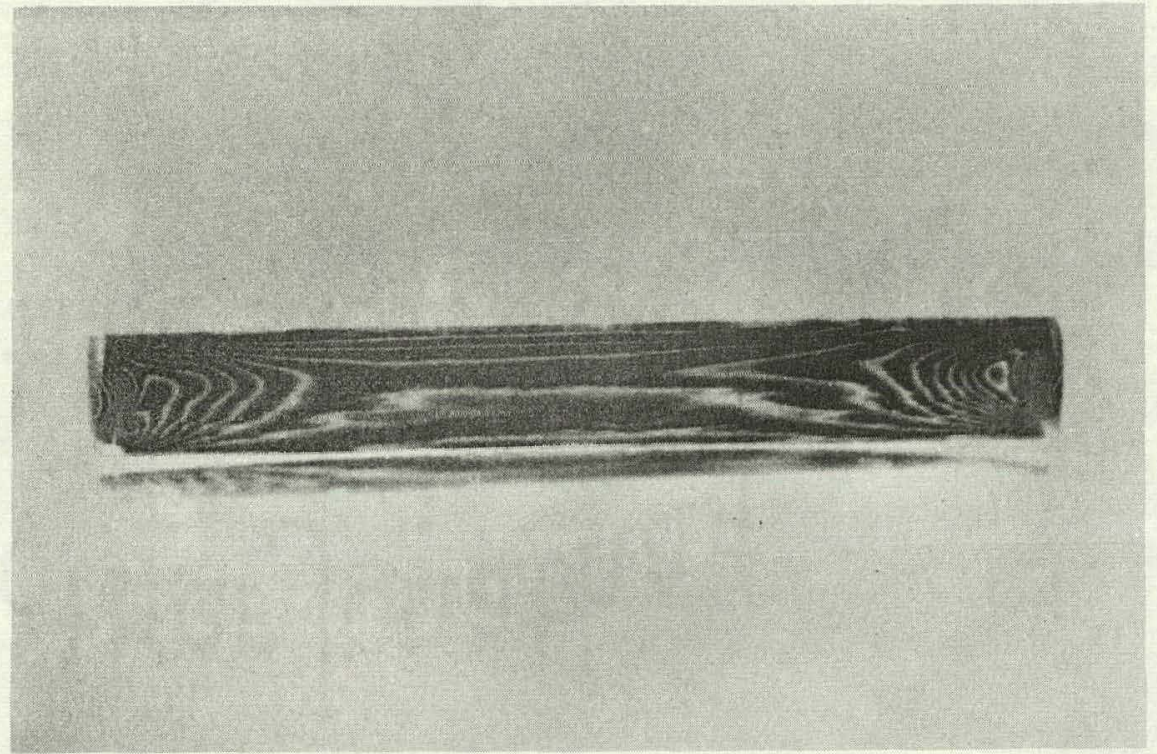

Figure 12. Photoplasticity fringes for a model after rolling. The similarity between this pattern and that of the compression blocks of Figure 4 is striking 


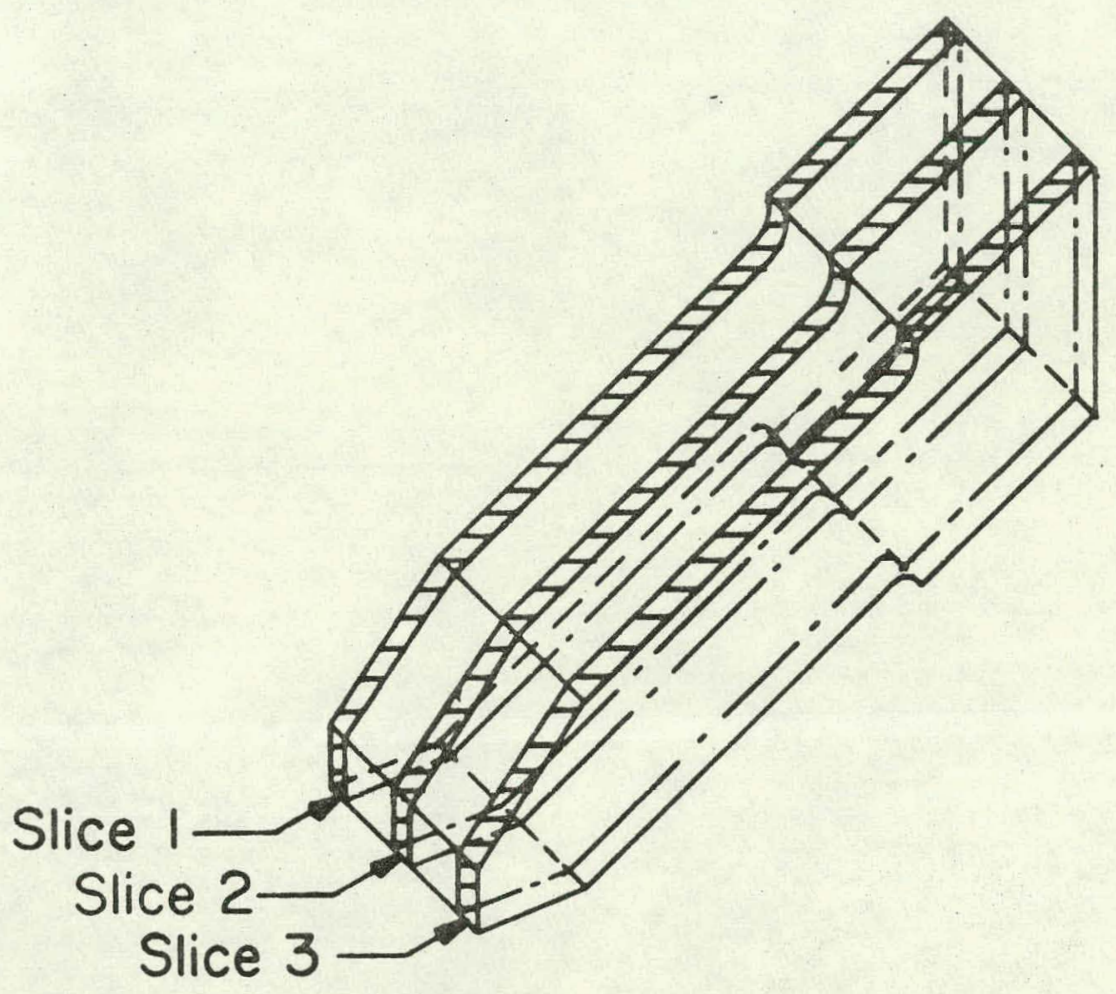

Figure 13a. Sketch to show how longitudinal slices were taken from the rolled block at $40^{\circ} \mathrm{C}$ 


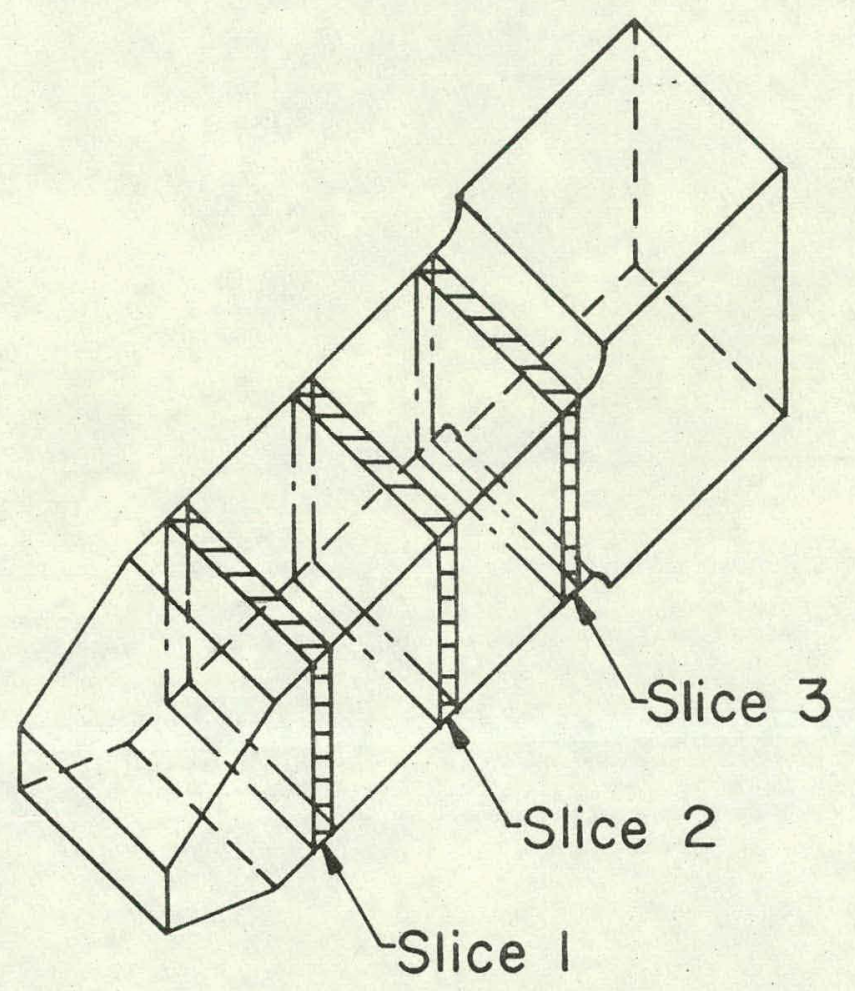

Figure 13b. Sketch to show how transverse slices were taken from the block rolled at $40^{\circ} \mathrm{C}$ 


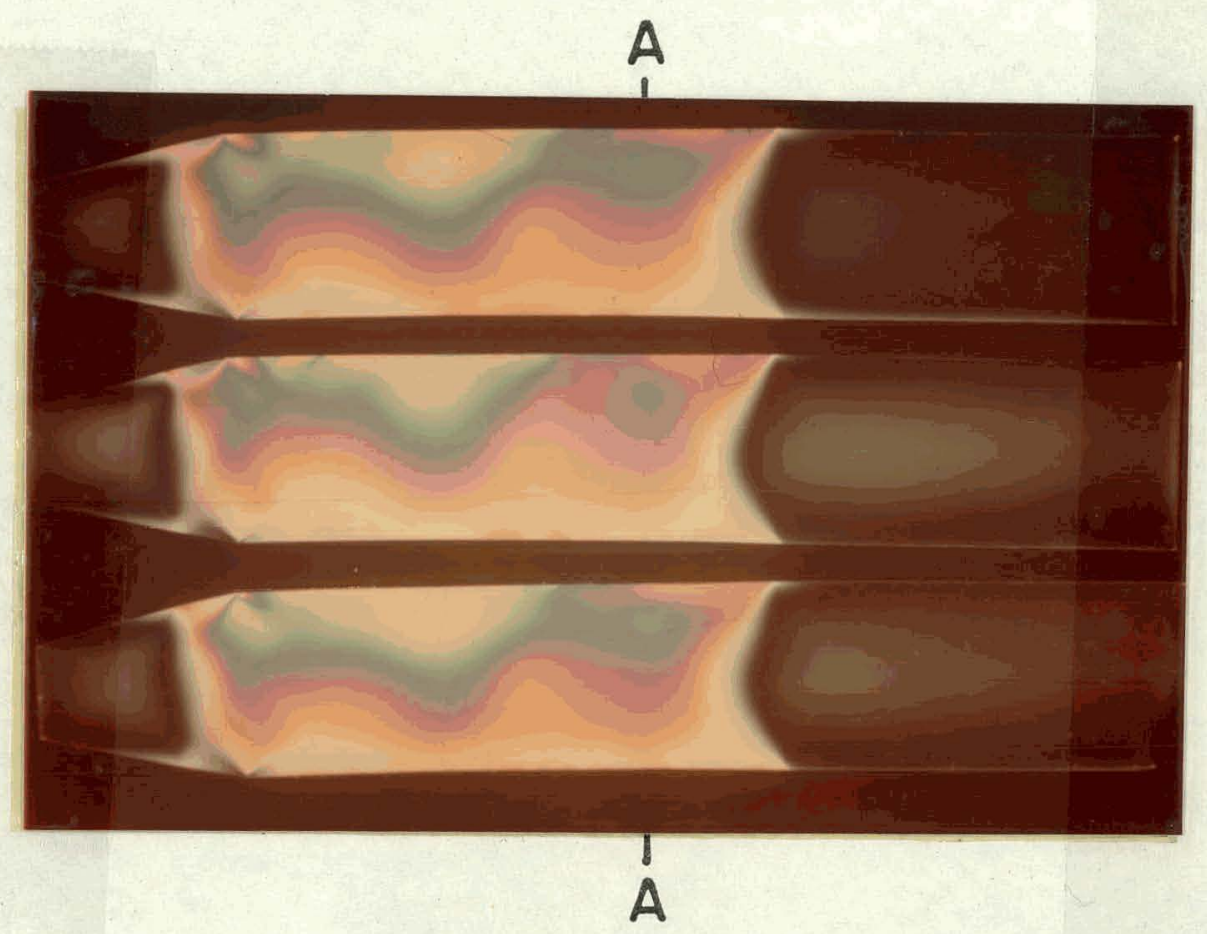

Figure 14a. Color photograph of slices taken from model as shown in Figure $13 a$

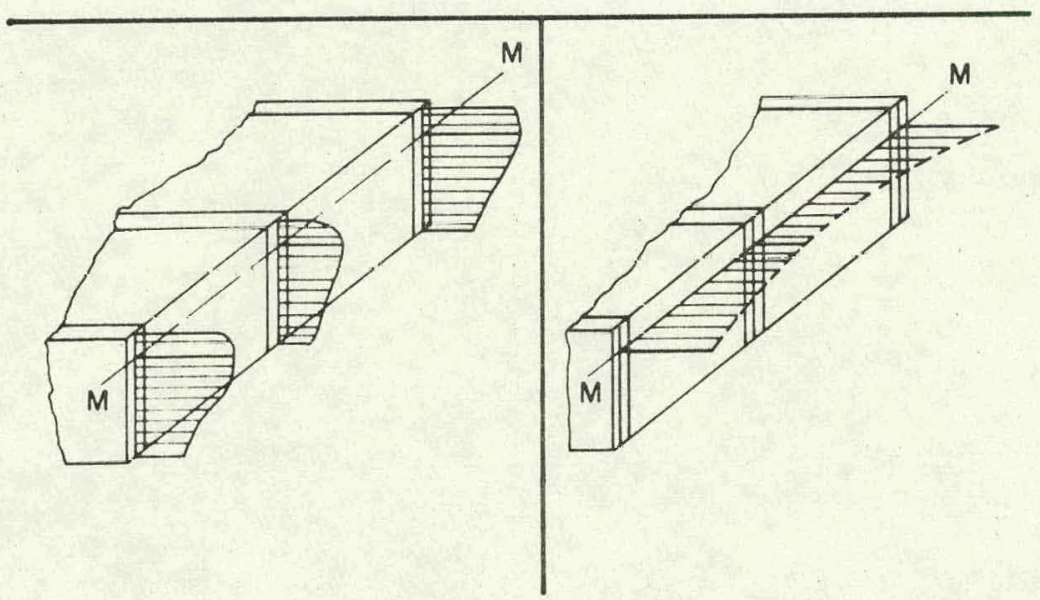

Figure 14b. Three dimensional depiction of photoplastic fringe

(N) from three

Figure 14c. Fringe distribution at position $\mathrm{M}-\mathrm{M}$ as filled in from maximum slices as shown in Figure $14 \mathrm{a}$ values in Figure $14 \mathrm{~b}$ 


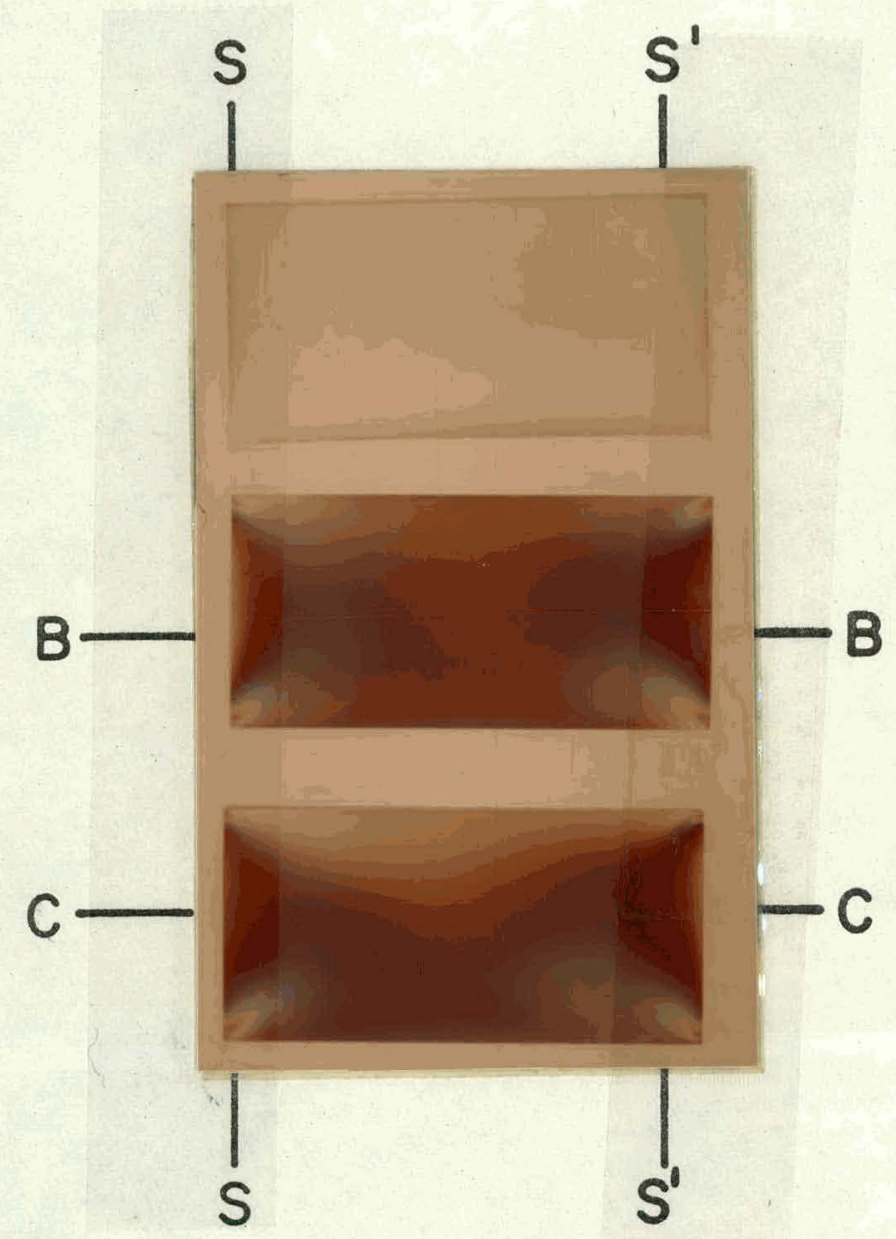

Figure 15a. Color photograph taken from model as shown in Figure $13 \mathrm{~b}$

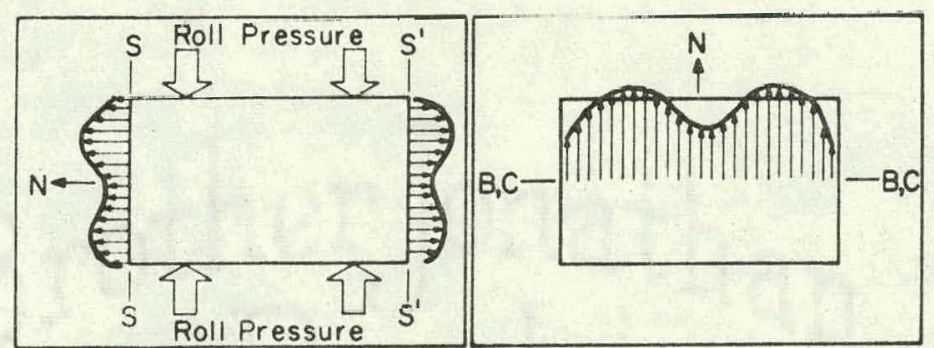

Figure 15b. Photoplastic fringe values

Figure 15c. Photoplastic fringe (N) along the two edges of the model values $(\mathrm{N})$ along position $\mathrm{B}-\mathrm{B}$ or $\mathrm{C}-\mathrm{C}$ as shown in Figure $14 \mathrm{a}$ 


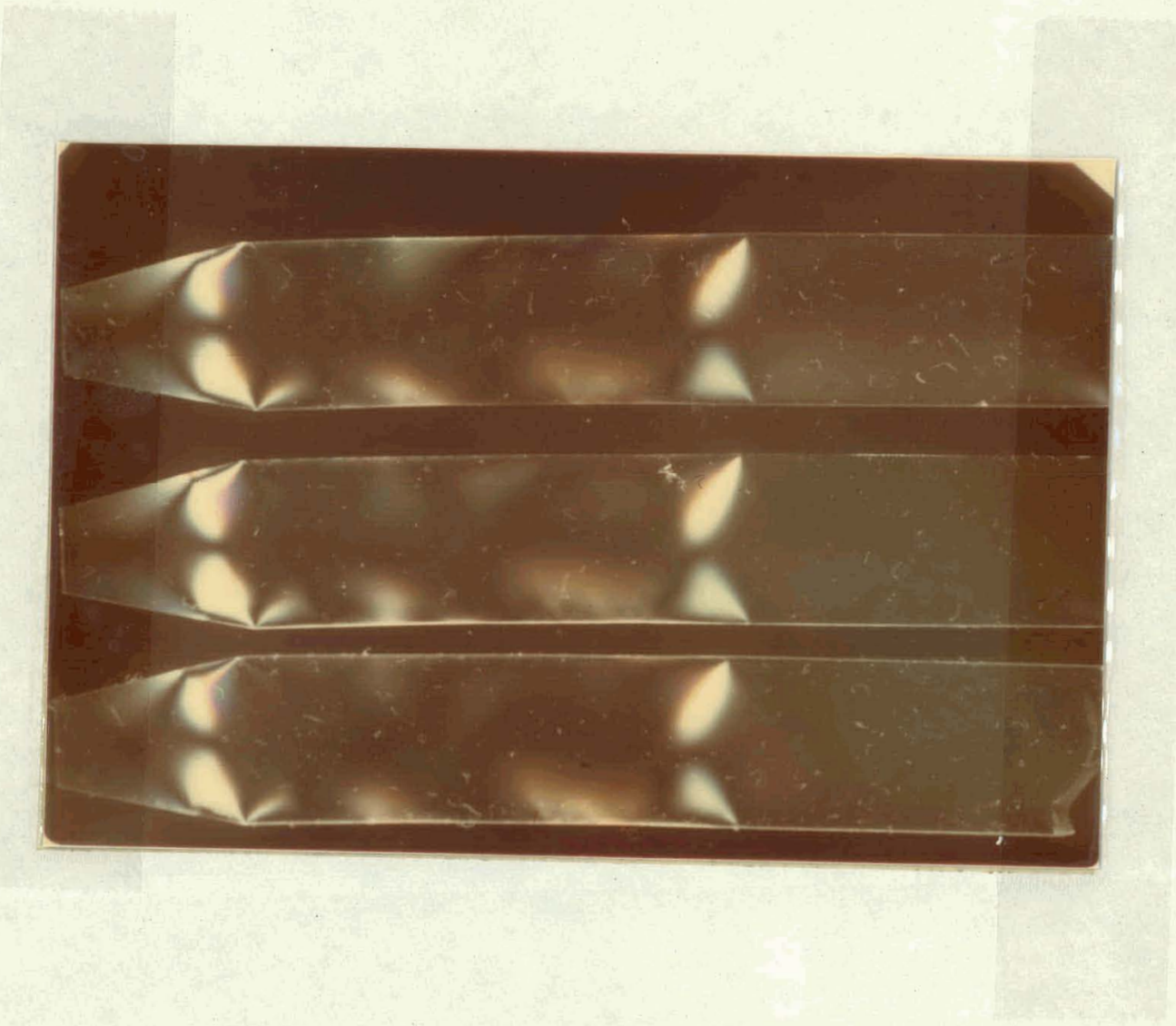

Figure 16. Isoclinics of the slices taken from model as shown in Figure $13 a$ 


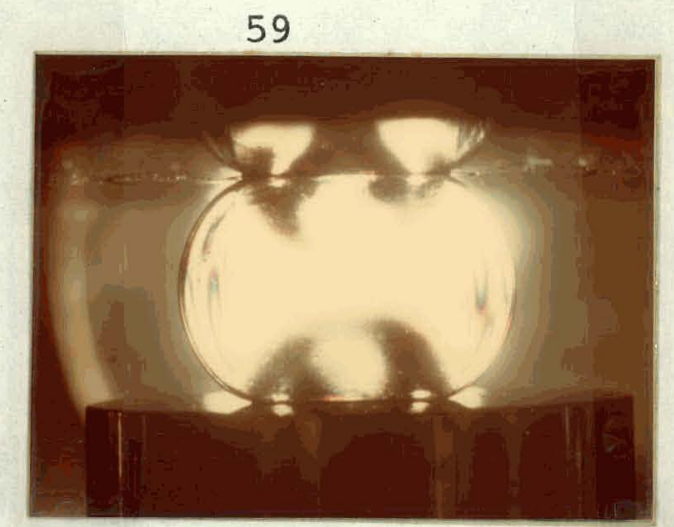

Figure 17a. Photoplasticity fringes of the disc under loading

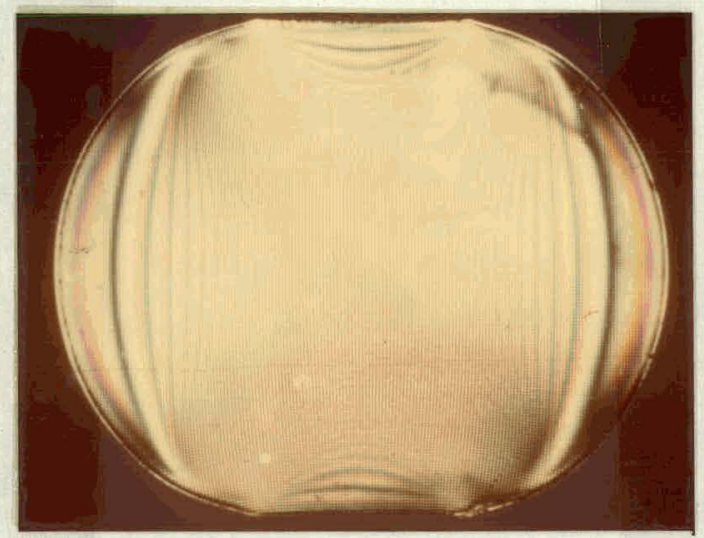

Figure 17b. Photoplasticity fringes of the disc shortly after the load was removed showing the change in fringe pattern due to the springback

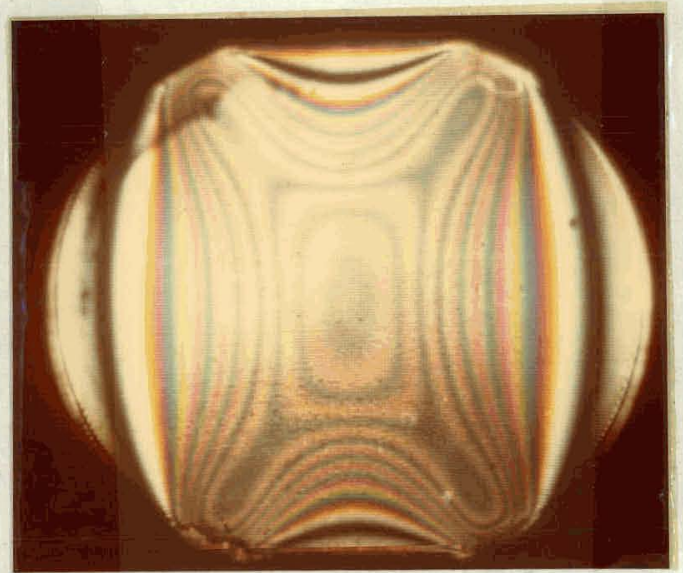

Figure 17c. Photoplasticity fringes of the disc six days after the load was removed showing the slow change in fringe pattern due to viscoelastic creep of the material 


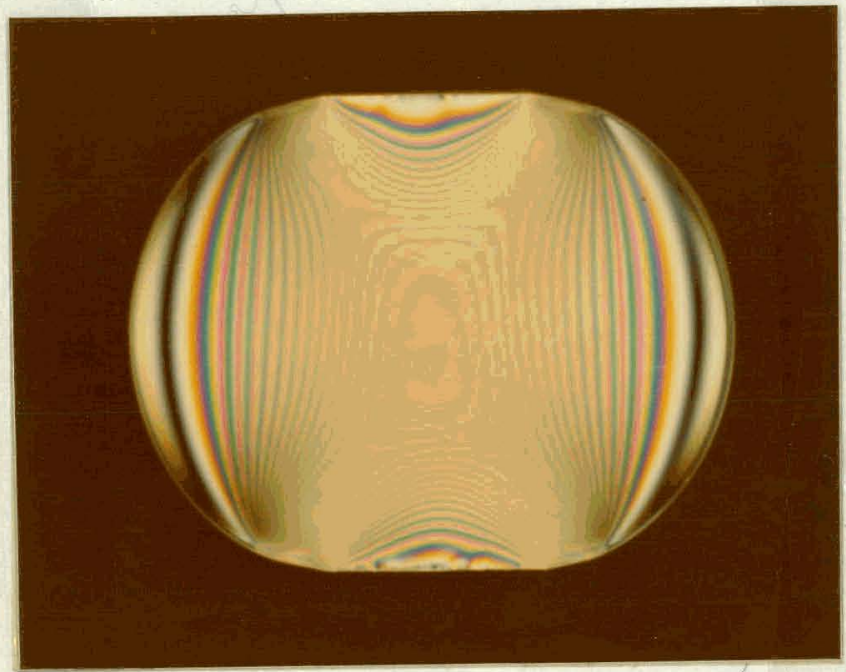

Figure 18a. Photoplasticity fringes of the disc compressed at $40^{\circ} \mathrm{C}$ and cooled to room temperature

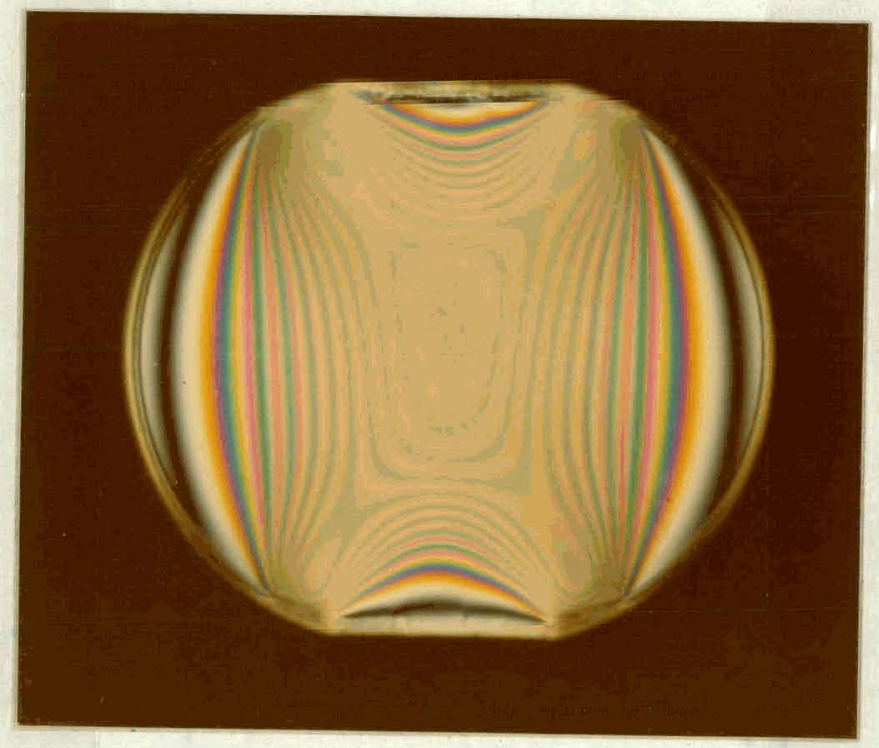

Figure 18b. Photoplasticity fringes of the disc (compressed at $40^{\circ} \mathrm{C}$ ) six days later 


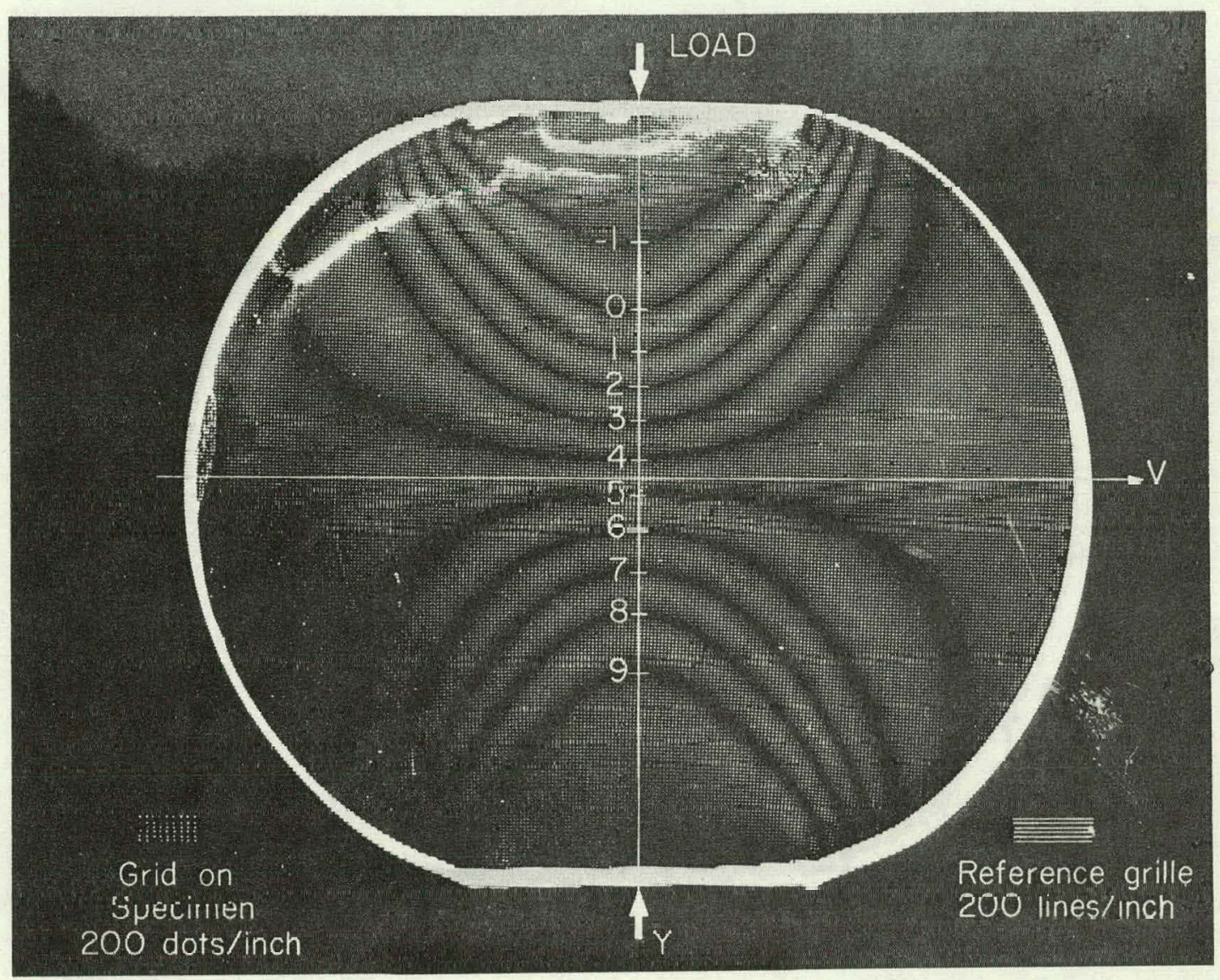

Figure 19a. Disc under diametral compression (vertical displacement) 


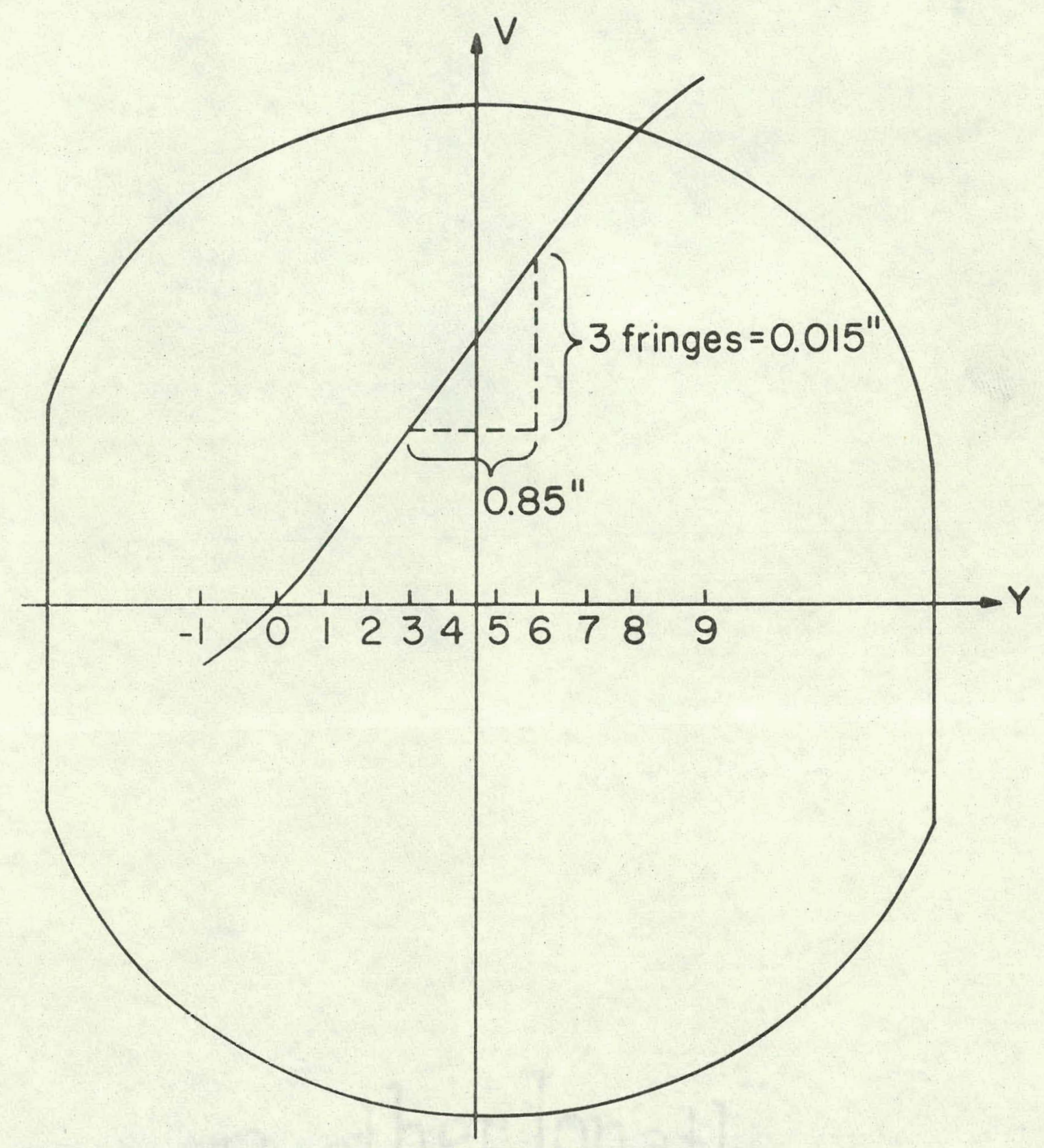

Figure 19b. Displacement-distance curve plotted to obtain $\varepsilon_{y}$ 


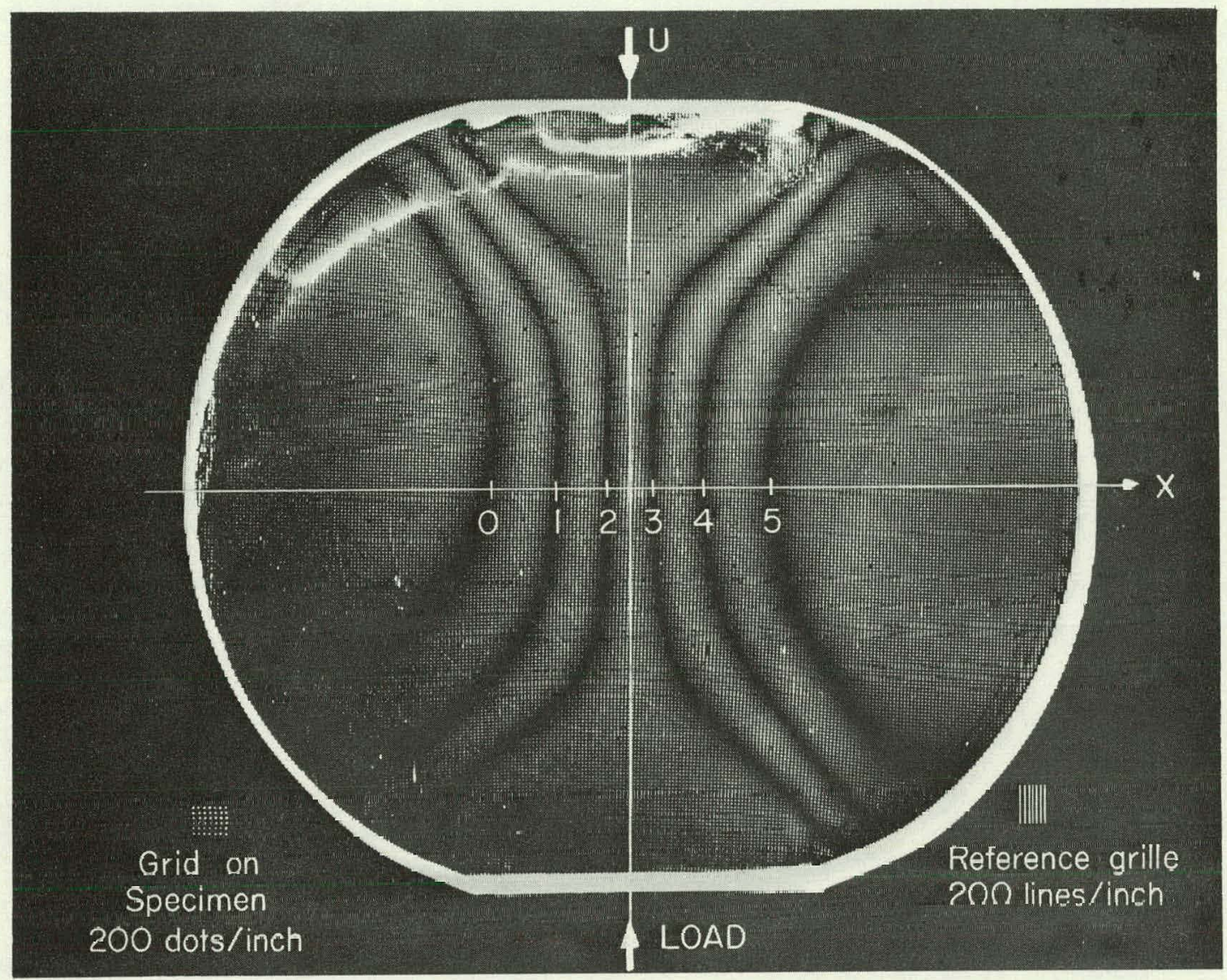

Figure 20a. Disc under diametral compression (horizontal displacement) 


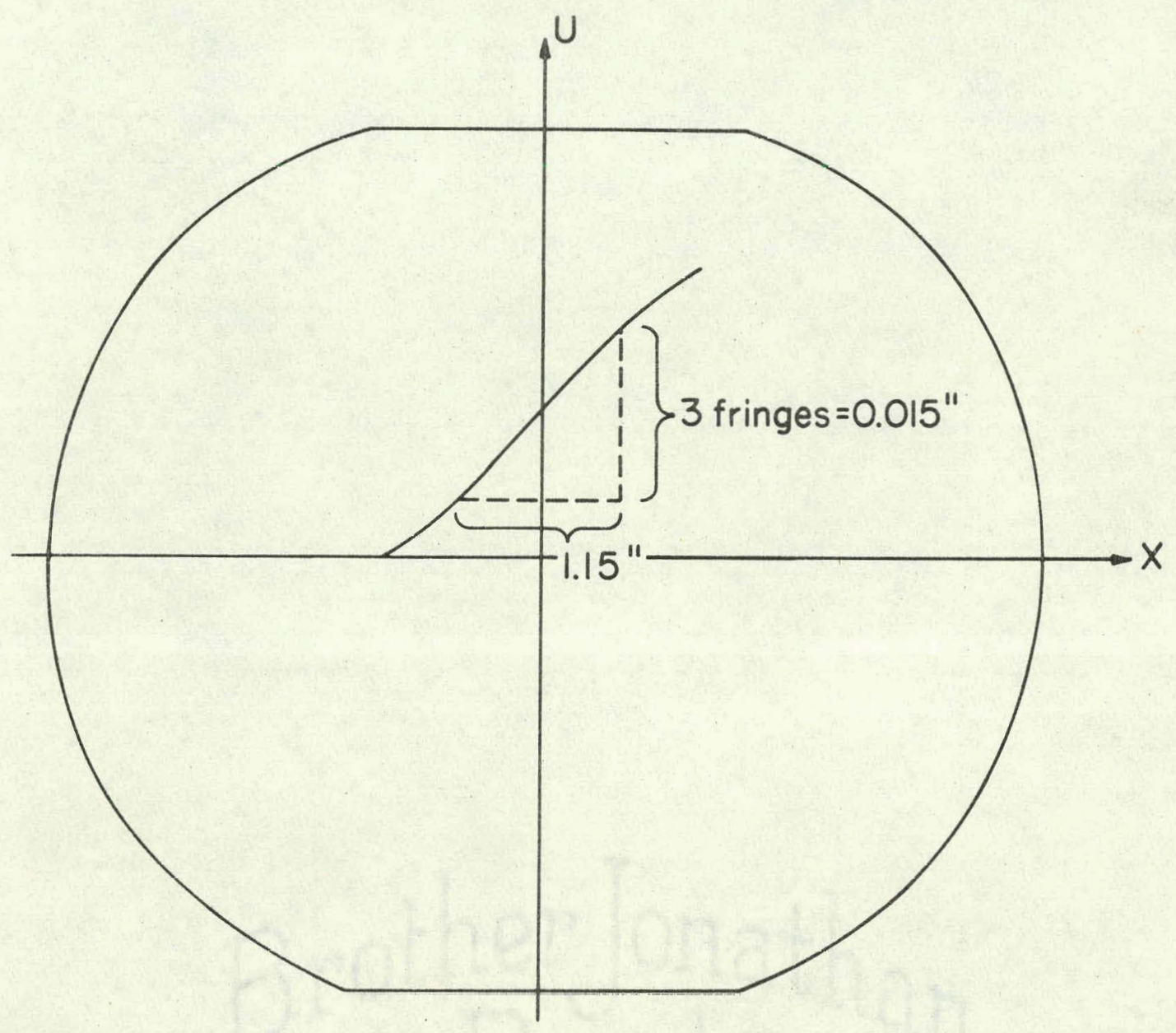

Figure 20b. Displacement-distance curve plotted to obtain. $\varepsilon_{\mathrm{x}}$ 


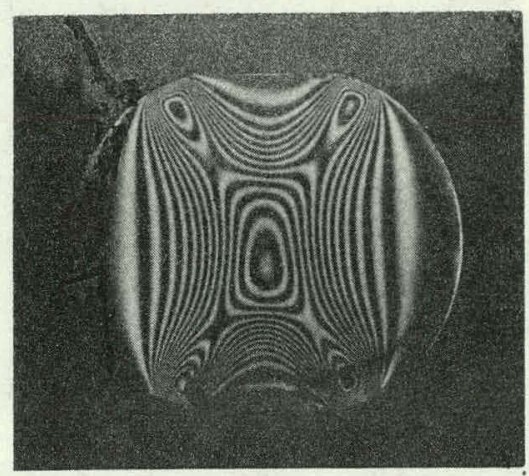

Figure 2la. Dark-field isochromatic fringe pattern of the disc loaded in diametral compression

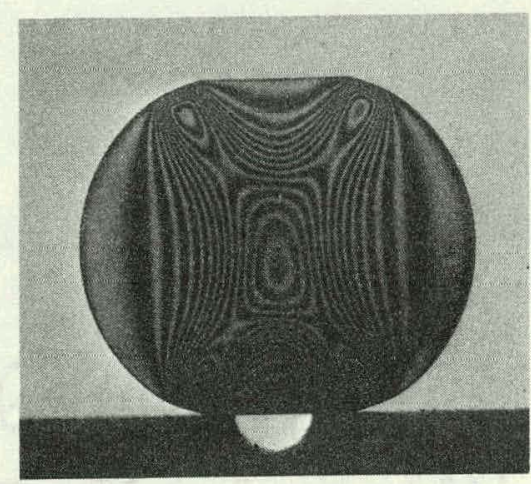

Figure 21b. Light-field isochromatic of the disc load in diametral compression

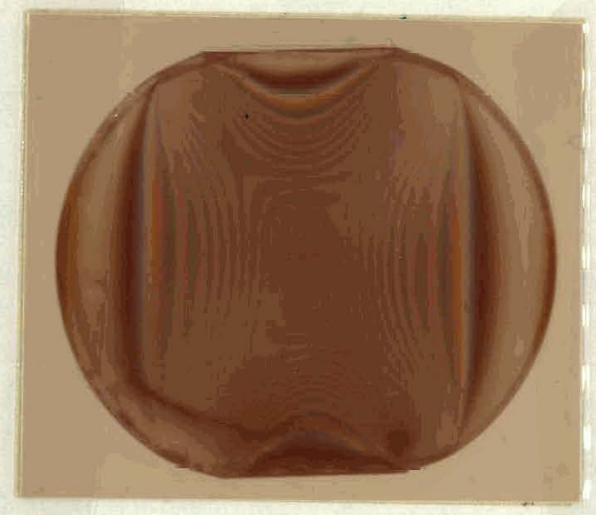

Figure 21c. Color photoplasticity fringes of the strain field 


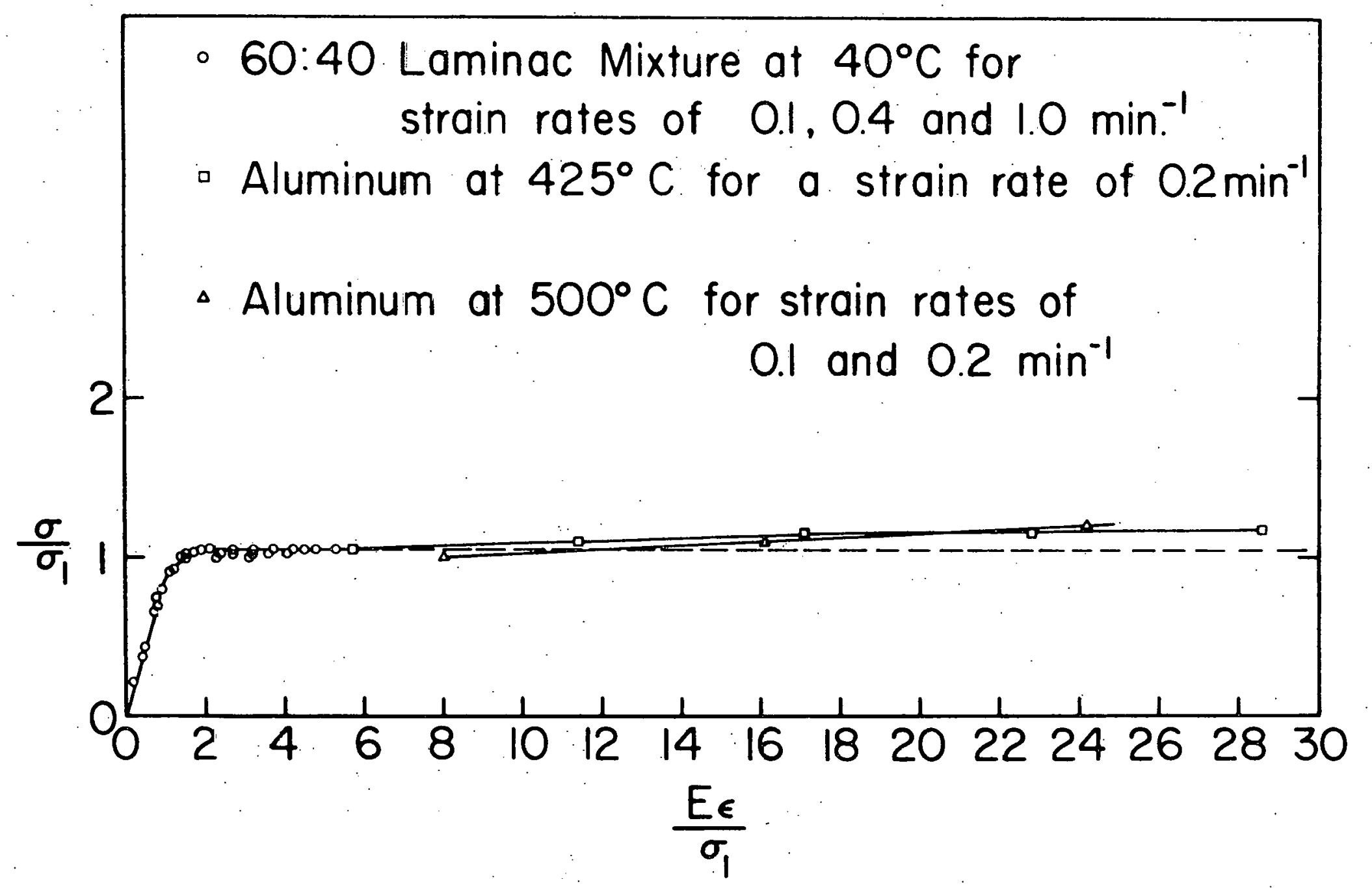

Figure 22. Comparison of stress-strain curves for aluminum at $425^{\circ} \mathrm{C}$ and $500^{\circ} \mathrm{C}$ with the $60: 40$ Laminac mixture at $40^{\circ} \mathrm{C}$ plotted according to the Ramberg-osgood relation 


\section{APPENDIX B \\ The Determination of the Material Fringe Constant $\mathrm{f}_{\varepsilon}$}

Before demonstrating how the material fringe constant is obtained, the development of the stress optic equation, $\sigma_{1}-\sigma_{2}=\frac{N f_{\sigma}}{h}$, is worth mentioning.

Sir David Brewster (27) discovered in 1816 that certain isotropic materials became double refracting (i.e., birefringent) when stressed. He found, for instance, that a plate of glass under a simple compressive stress acquired the ability to polarize light which is incident normal to its plane, along two mutualiy perpendicular axes. These axes coincide at any point in the plane of the plate, with the directions of the principal stresses in that plane.

In travelling through the thickness of the glass, the two waves, therefore, become out of phase i.e., they acquire a relative phase shift or relative retardation which is, a) proportional to the thickness of the plate', b) proportional to the difference between the two principal stresses $\sigma_{1}$ and $\sigma_{2}$. Material is generally referred to as being negative birefringent when the velocity of $\sigma_{2}$ is greater than that of $\sigma_{1}$. If the velocity of $\sigma_{2}$ was less than that of $\sigma_{1}$ it would have been positive birefringent. This birefringence is temporary, i.e., it disappears when the stress is removed. This work was conducted within the limit of elasticity. 
In 1841, Neumann (28) carried out the first investigation of the theory of artificial double refraction in a solid subjected to any system of forces. He attributed the temporary birefringence to the strain in the body and obtained his results in terms of strain. In 1852 Maxwell (29), apparently unaware of Neumann's work, carried out a similar investigation, using stresses instead of strains and obtained results of precisely the same form. The laws formulated by Neumann (28) and Maxwell (29) stated in terms of stress, are as follows 1) at any point in a stressed transparent solid the axes of polarization of light passing through the solid are parallel to the directions of the principal stresses in the plane of the wave-front at the point. 2). The difference of the velocities of the two polarized rays at the point is proportional to the difference of these two principal:stresses, and is independent of stresses perpendicular to the plane of the wave-front. Thus the directions of polarization will be the directions of the principal axis of the stress-conic in the plane of the wave-front.

The changes in the indices of refraction as noted by Maxwell were linearly proportional to the stresses induced in the model and followed the relationships

$$
\begin{aligned}
& \mathrm{n}_{1}-\mathrm{n}_{0}=c_{1} \sigma_{1}+c_{2} \sigma_{2} \\
& \mathrm{n}_{2}-\mathrm{n}_{0}=c_{1} \sigma_{2}+c_{2} \sigma_{1}
\end{aligned}
$$


where $\mathrm{n}_{0}$ is the index of refraction of the model in the unstressed state, $n_{1}, n_{2}$ are the indices of refraction along the two principal axes associated with $\sigma_{1}$ and $\sigma_{2}$, respective1y. $c_{1}, c_{2}$ are the stress optic coefficients. Subtracting Equation (1) and (2) we obtain

$$
\mathrm{n}_{1}-\mathrm{n}_{2}=\left(c_{1}-c_{2}\right)\left(\sigma_{1}-\sigma_{2}\right)
$$

The stressed, photoelastic model exhibits properties very similar to those of wave plates employed in the photoelastic polariscope since the materials they are made of have the ability to resolve the light vector into two orthogonal components and, moreover, the ability. to transmit each of these components at a different velocity. Based on this difference, the two components will emerge from the plate at different times. One component is retarded timewise relative to the other component. To obtain the relative phase shift between the two components, the angular retardation $(\Delta)$ for each component should be considered.

$$
\begin{aligned}
& \Delta_{1}=\frac{2 \pi h}{\lambda}\left(n_{1}-n\right) \\
& \Delta_{2}=\frac{2 \pi h}{\lambda}:\left(n_{2}-n\right)
\end{aligned}
$$

where $n$ is the index of refraction of air, $\Delta_{1}, \Delta_{2}$ are the angular retardation of the component of light travelling along principal axis 1 and 2 , respectively; $h$ is the thick- 
ness of the plate and $\lambda$ is the wave length of the light. The difference $\Delta_{1}-\Delta_{2}$ represents the angular phase shift or difference between the two components of light when they emerge from the wave plate (7).

$$
\begin{aligned}
& \Delta=\Delta_{1}-\Delta_{2}=\frac{2 \pi h}{\lambda} \cdot\left(n_{1}-n_{2}\right) \\
& n_{1}-n_{2}=\frac{\lambda \Delta}{2 \pi h}
\end{aligned}
$$

By substituting Equation (7) into Equation (3) we obtain:

$$
\Delta=\frac{2 \pi h}{\lambda}\left(c_{1}-c_{2}\right)\left(\sigma_{1}-\sigma_{2}\right)
$$

If $c_{1}-c_{2}$ is set equal to $c$, the relative stress optic coefficient, the relative retardation is given by:

$$
\Delta=\frac{2 \pi h C}{\lambda}\left(\sigma_{1}-\sigma_{2}\right)
$$

Equation (9) is the classic description of the stress optic law. Putting

$$
\mathrm{N}=\frac{\Delta}{2 \pi} \begin{aligned}
& \text { as the relative retardation in terms of a } \\
& \text { complete cycle of retardation, } 2 \pi \text { (dimension- } \\
& \text { less) }
\end{aligned}
$$

and

$$
\mathrm{f}_{\sigma}=\frac{\lambda}{\mathrm{C}} \text { as the material fringe value psi-in. }
$$

Equation (9) then becomes

$$
\sigma_{1}-\sigma_{2}=\frac{N f_{\sigma}}{h}
$$


Equation (10) is valid in the elastic region only and for linear elasticity may be written as $\varepsilon_{1}-\varepsilon_{2}=\frac{N f_{\varepsilon}}{h}$ where $f_{\varepsilon}=\frac{1+v}{E} f_{\sigma}$. From Neumann's work it is not surprising to find that in the plastic range $\left(\varepsilon_{1}-\varepsilon_{2}\right)=\frac{N E}{h}$ is generally also valid. Here the property $f_{\varepsilon}$ may or may not be constant depending on the actual photoplastic material. In order to find the relationship between $f_{\varepsilon}$ and $\left(\varepsilon_{1}-\varepsilon_{2}\right)$ the Moire method was used to find the $\varepsilon_{1}$ and $\varepsilon_{2}$ separately. A disc given a reduction of 208 is used here as an example to show the detailed calculation involved. Figures 19 and 20 are used for this purpose. Both photographs, 19a and 20a, are of the same disc after compression. The original disc had printed onto its surface a fine grid pattern which effectively resulted in a crossed dot pattern of 200 dots per inch. This pattern can be seen enlarged on both photographs. The pattern was plastically deformed when the disc was loaded in the y-direction. Thus plastic deformation of the grid remained after loading. The disc was then laid with the grid face down onto a photographic plate so that a contact photograph of the deformed pattern could be taken. After the development of this contact negative, two separate pictures were taken. In the first a reference grille of 200 lines per inch was laid over the contact negative with the line in the $x$-direction. This reference grille interfered with the deformed dot patterns to give Moiré lines or fringes which can 
be used to find the displacement in the $y$-direction. This Moiré pattern is shown enlarged in Figure 19a.

In accord with most elasticity and plasticity conventions, the displacements in the $y$-direction are designated as $v$ and those in the $x$-direction as $u$. The strains relate to the displacements such that $\varepsilon_{x}=\frac{\partial u}{\partial x}$ and $\varepsilon_{y}=\frac{\partial v}{\partial y}$, i.e., the slope of the line drawn in Figure 19b, which is merely a graphical plot of the consecutive spacing of the Moiré fringes along the $y$-axis, is important. The individual numbèr given to any Moiré fringe is not significant and the position "O" and the subsequent number were chosen arbitrarily. The fringe pattern on its: own does not show whether the strains are positive or negative. The technique (30), used to determine whether the strain is positive or negative is that the reference grille is superimposed on the contact print of the deformed specimen cross grid, thereby producing a family of Moiré fringes. A relative angular displacement of the reference grille will make the Moiré fringes to either follow the direction of the angular displacement of the reference grille if the strain is tensile (positive) or are angularly displaced in the direction opposite to that of the reference grille if the strain is compressive (negative). Using this technique, it was found that the strain in the $y$-direction was negative.

After obtaining the plot in Figure $19 \mathrm{~b}$ the slope of the 
curve $\frac{\Delta v}{\Delta y}$ was determined at the center of the disc and the value obtained gave the number of fringes per inch at the center $i . e ., \frac{1}{f}$ where $f$ is the distance between adjacent fringes. Multiplying the value of the slope by the grid pitch (P) which was $\frac{1}{200}$ inch in this case, gave the appropriate strain component, $\left(\varepsilon_{y}\right)$, at the center of the disc which should be assigned a negative value as previously. established.

Since the resulting Moiré fringe photograph Fiqure 19a was enlarged to enhance easy plotting of the curve, a scale must be established to correlate distance measured on the enlarged photograph with distance on the compressed disc. The vertical distance between the piattens along the $y$ axis after the disc was compressed was 1.0625 inches. This distance corresponds to 6 inches in the enlarged photograph of the disc after compression, Figure 19a. Therefore, one inch on the enlarged photograph corresponds to $\frac{1.0625}{6.0}=$ 0.1771 inch on the disc.

From Figure $19 \mathrm{~b}, 0.4$ inch represents one fringe. Therefore, the slope,

$$
\Delta v=\frac{3 \text { fringes }}{0.85^{0}}-\frac{3 \text { fringes }}{(0.1771)(0.85)}=\frac{3 \text { fringes }}{0.15052}
$$

Since there is no initial mismatch because the pitch of the specimen grid is equal to the pitch of the reference grid, one fringe is equal to a displacement of $\frac{1}{200}$ or 0.005 inch. 
Thus, 3 fringes $=0.015$ inch and

$$
\varepsilon_{y}=\frac{-\Delta y}{\Delta y}=\frac{-3 \text { fringes }}{0.15052}=\frac{-0.015}{0.15052}=-0.09965=-9.965 \%
$$

By rotating the reference grid $90^{\circ}$ another family of Moiré fringes for the horizontal displacements was obtained, figure 20a. The fringe order versus position curve was plotted as Figure $20 \mathrm{~b}$ following the same steps used for Figure $19 \mathrm{~b}$ and the value of the slope at the center of the disc was determined. The strain was found to be positive by using the aforementioned technique.

The diameter of the disc after compression was 1.2500 inches which corresponds to 6.9 inches of the enlarged photograph of the disc in Figure 20a after compression. One inch of the enlarged photograph is $\frac{1.25}{6.9}=0.1800$ inches of the disc after compression. From Figure $20 \mathrm{~b}, 0.4$ inch represents one fringe. Therefore, the slope $\frac{\Delta u}{\Delta x}=\frac{3 \text { fringes }}{(1.15)(0.18)}=$ $\frac{3 \text { fringes }}{0.20800}:$ But 3 fringes $=0.015$ inch. Therefore $\varepsilon_{x}=$ $\frac{\Delta u}{\Delta x}=\frac{0.015}{0.20800}=0.07200=7.2008$. Substituting the values of $\varepsilon_{x}$ and $\varepsilon_{y}$ into the strain optic equation, $\varepsilon_{x}-\varepsilon_{y}=\frac{N f}{h}, f_{\varepsilon}$ can be determined. $N$, the fringe order for birefringence at the center of the disc was determined accurately from the dark field, light field, and color isochromatic fringes in Figure $21 a, b, c$. Its value was found to be 12 and the thickness of the disc, h, was 0.375 inch. 


$$
\text { Thus, } \begin{aligned}
f_{\varepsilon} & =\frac{\left(\varepsilon_{x}-\varepsilon_{y}\right) h}{N} \\
& =\frac{(0.72+0.09965)(0.375)}{12} \\
& =\frac{(0.17165)(0.375)}{12} \\
& =0.0053641 \mathrm{in} / \mathrm{in} / \text { fringe }
\end{aligned}
$$

or

$$
\mathrm{f}_{\varepsilon}=0.536418 / \text { fringe } .
$$

